FEDERAL RESERVE BANK OF SAN FRANCISCO

WORKING PAPER SERIES

\title{
Dynamic Labor Reallocation with Heterogeneous Skills and Uninsured Idiosyncratic Risk
}

\author{
Ester Faia \\ Goethe University Frankfurt and CEPR \\ Ekaterina Shabalina \\ Goethe University Frankfurt \\ Marianna Kudlyak \\ Federal Reserve Bank of San Francisco \\ June 2021 \\ Working Paper 2021-16 \\ https://www.frbsf.org/economic-research/publications/working-papers/2021/16/
}

\section{Suggested citation:}

Faia, Ester, Ekaterina Shabalina, Marianna Kudlyak. 2021 "Dynamic Labor Reallocation with Heterogeneous Skills and Uninsured Idiosyncratic Risk," Federal Reserve Bank of San Francisco Working Paper 2021-16.

https://doi.org/10.24148/wp2021-16

The views in this paper are solely the responsibility of the authors and should not be interpreted as reflecting the views of the Federal Reserve Bank of San Francisco or the Board of Governors of the Federal Reserve System. 


\title{
Dynamic Labor Reallocation with Heterogeneous Skills and Uninsured Idiosyncratic Risk*
}

\author{
Ester Faia ${ }^{\dagger}$ \\ Goethe University Frankfurt and CEPR \\ Marianna Kudlyak ${ }^{\ddagger}$ \\ Federal Reserve Bank of San Francisco and CEPR \\ Ekaterina Shabalina $§$ \\ Goethe University Frankfurt \\ June 10, 2021
}

\begin{abstract}
Occupational specificity of human capital motivates an important role of occupational reallocation for the economy's response to shocks and for the dynamics of inequality. We introduce occupational mobility, through a random choice model with dynamic value function optimization, into a multi-sector/multi-occupation Bewley (1980)Aiyagari (1994) model with heterogeneous income risk, liquid and illiquid assets, price adjustment costs, and in which households differ by their occupation-specific skills. Labor income is a combination of endogenous occupational wages and idiosyncratic shock. Occupational reallocation and its impact on the economy depend on the transferability of workers' skills across occupations and occupational specialization of the production function. The model matches well the statistics on income and wealth inequality, and the patterns of occupational mobility. It provides a laboratory for studying the short- and long-run effects of occupational shocks, automation and task encroaching on income and wealth inequality. We apply the model to the pandemic recession by adding an SIR block with occupation-specific infection risk and a ZLB policy and study the impact of occupational and aggregate labor supply shocks. We find that occupational mobility may tame the effect of the shocks but amplifies earnings inequality, as compared to a model without mobility.
\end{abstract}

JEL: J22, J23, J31, J62, E21, D31.

Keywords: Occupational Mobility, Heterogeneous Agents, Skills, Income and Wealth Inequality, Discrete Choice Optimization.

* Any opinions expressed are those of the authors and do not reflect those of the Federal Reserve Bank of San Francisco or the Federal Reserve System. Ester Faia gratefully acknowledges support from the DFG grant FA-1022-2. The authors thank Ludwig Straub for his generous help with the solution algorithm and Benjamin Moll and Ricardo Reis for helpful comments. The authors thank Max Mayer for excellent help with the k-means algorithm.

† faia@wiwi.uni-frankfurt.de

† marianna.kudlyak@sf.frb.org

$\S$ ekaterina.pyltsyna@gmail.com 


\section{Contents}

1 Introduction $\quad 3$

2 Related Literature $\quad 8$

3 Heterogenous Agents Model with Dynamic Occupational Choice and $\begin{array}{lr}\text { Idiosyncratic Income Risk } & 10\end{array}$

3.1 Consumption-Saving and Occupational Choice . . . . . . . . . . . . . . . 11

3.2 Heterogeneous Firms: Labor Demand, Capital Demand, and Pricing Decisions 17

3.3 Asset Returns . . . . . . . . . . . . . . . . . . . . . . . . . 19

3.4 Monetary and Fiscal Policy . . . . . . . . . . . . . . . . . 20

3.5 SIR Block . . . . . . . . . . . . . . . . . . . . . 20

3.6 Market Clearing: Labor, Goods and Asset Markets . . . . . . . . . . . . . . 21

3.7 Equilibrium . . . . . . . . . . . . . . . . . . . 22

4 Analytical Results $\quad 23$

5 Model Parametrization and Solution Method $\quad 24$

5.1 Skills, Occupations and Skills Distribution . . . . . . . . . . . . . . . 24

5.2 Sectors and Production Function . . . . . . . . . . . . . . . . . 27

5.3 Other Parameters . . . . . . . . . . . . . . . . . . . . . . . . . . 28

5.4 Solution Method . . . . . . . . . . . . . . . . . . 30

6 Quantitative Results 31

6.1 Steady State Results . . . . . . . . . . . . . . . . . . . . . . 31

6.1.1 Occupational Sorting . . . . . . . . . . . . . . . . . 31

6.1.2 Income and Wealth Distributions . . . . . . . . . . . . . . . . . 33

6.2 Dynamic Responses to Standard Monetary Policy Shock . . . . . . . . . . . 35

7 An Application of the Model to the Pandemic Recession $\quad 37$

7.1 Occupational Shocks . . . . . . . . . . . . . . . . . . 38

7.2 The Role of Monetary Policy . . . . . . . . . . . . . . . . . . . . . . . . . 41

7.3 The Role of Job Specialization and Skill-Transferability . . . . . . . . . . . . 43

7.4 Sectoral Productivity Shocks in a Two-Sector Model . . . . . . . . . . . . . . 45

7.5 Aggregate Labor Supply Shock in an One-Sector Model . . . . . . . . . . . . . 48

7.6 Dynamic Response to Combined Aggregate Supply and Occupational Shocks 51

8 Conclusions $\quad 53$

$\begin{array}{ll}\text { A Derivations of Analytical Results } & 61\end{array}$

$\begin{array}{ll}\text { B Computation Method } & 65\end{array}$

C Constructing Occupational Clusters Using k-means Algorithm 68

$\begin{array}{ll}\text { D Appendix Tables } & 70\end{array}$

$\begin{array}{ll}\text { E Other Quantitative Results } & 70\end{array}$

$\begin{array}{lll}\text { F } & \text { Wealth Distribution Graphs } & 73\end{array}$ 


\section{Introduction}

The role of worker and job reallocation in an economy's response to shocks and its impact on inequality is one of the fundamental questions in economics (Schumpeter (1942)). The focus has been on sectoral shocks and the ensuing reallocation across sectors (Lilien (1982)). The shocks, however, often fail to generate large aggregate disturbances as there is little barrier to sectoral labor reallocation. Instead, the literature finds that workers' skills or, broadly, human capital are closely related to occupational tasks (Gathmann and Schönberg (2010), Guvenen, Kuruscu, Tanaka and Wiczer (2020)). Consequently, the degree of skill transferability and substitutability of occupational hours in the production function play a central role for worker and job reallocation. Given this technological side, reallocation is a result of an interplay of the type of shocks, skills, wages and wealth, whereby the latter affects workers' decision of shifting labor supply across occupations. Occupational reallocation is particularly important for understanding the effects of technological shocks that change occupational tasks (see, for example, Autor, Levy and Murnane (2003)). Studying the interplay of these forces and the impact of occupational reallocation on the macroeconomy and inequality requires a dynamic macro model with optimal occupational decision in an environment where agents are heterogeneous in terms of their skills and wealth accumulation, that is, uninsurable idiosyncratic risk.

We introduce endogenous occupational mobility, through a discrete choice with value function optimization based on workers' comparative advantage in Roy (1951)'s tradition, in a general equilibrium multi-sector and multi-occupation Bewley (1980)-Aiyagari (1994)-style model with idiosyncratic income shocks, liquid and illiquid assets and in which agents differ with respect to their occupational-specific skills. In the model, occupational choice depends on skills as well as wealth and income risk. Our dynamic discrete occupational choice set-up with Gumbel-distributed taste shocks follows Rust (1987). Taste shocks capture the role of compensating differentials and other non-pecuniary aspects such as job amenities (see Taber and Vejlin (2020)). Income inequality in the model is linked to the occupational choice and depends both on idiosyncratic income shocks (luck) and skills (talent or human capital). The 
model also features sticky prices to examine the role of reallocation in the short-run, while taking into account the role of stabilization policies.

Workers in the model belong to one of a discrete set of types that differ in their skills and, therefore, efficiency units that they can provide in different occupations. The skill distribution matrix of worker types across occupations captures workers' comparative advantage and, hence, in the Roy tradition, is a key determinant of occupational choice and mobility. Each period, workers experience idiosyncratic productivity shocks. They choose which occupation to work at or whether to stay out of employment, an option which provides a fixed flow value. We model occupational decision through a random discrete choice problem in which workers compare value functions in each occupation. These value functions depend on workers' skill, wealth and idiosyncratic income shocks. Imperfect skill-transferability or job specialization govern the extent of mobility. Our model with endogenous occupational choice complements recent work by Eeckhout and Sepahsalari (2020) who built a directed search model with uninsurable risk that links wealth accumulation and occupational sorting.

Labor income in our model includes both an idiosyncratic exogenous component and occupational wages, which are endogenously determined via labor market clearing in each occupation. Wages depend on the skill distribution, which characterizes worker's skills transferability across occupations, and the job specialization, which characterizes imperfect substitutability of occupations in the sectoral production function. Hence, our model endogenizes the cross-sectional distribution in income, i.e., income inequality.

We derive a set of analytical results focusing on the technological side of reallocation, that is, on the extent to which aggregate and cross-sectional changes in labor demand affect reallocation. We show that allocation of labor across occupations and sectors depends on the primitives which affect labor demand, i.e., the occupational weights and the degree of occupational substitutability in the production function, and labor supply, i.e., the skill distribution in the population. We also show that changes in occupational substitutability affect the elasticity of occupational labor demand with respect to wages and the aggregate capital-labor substitution. Finally, lower job substitutability, by raising job specialization, 
raises occupational rents (i.e., mark-ups) and serves a role akin to occupational mobility costs.

We solve the model using the sequence-space Jacobian method developed by Auclert, Bardóczy, Rognlie and Straub (2019) for general equilibrium heterogeneous agent models in discrete time with expectations. We extend the method by adding a guess-and-verify procedure for solving the two-stage households' decisions problem, which involves a consumption-saving and a discrete-choice occupational decisions. Under the extreme type I taste shocks, the model delivers a closed-form solution for the occupational choice probabilities. In our application of the model to the pandemic, we adopt the fully non-linear routine from Auclert et al. (2019)'s algorithm to accommodate the transitional dynamics between steady states.

We parameterize novel elements of the model using micro data and employ the standard parameter values from the literature on heterogeneous agents models for the remaining parameters. One of the important primitives of the model is the skill distribution matrix of worker types across occupations. To construct the skill matrix, we group detailed occupations into broad occupational categories based on the proximity of the occupational tasks described in O-NET using a k-means machine learning algorithm (see also Bonhomme, Lamadon and Manresa (2017) and Grigsby (2020)). We then measure transferability of skills across the occupational categories based on the differences in occupational tasks using data from O-NET (see Poletaev and Robinson (2008) or Gathmann and Schönberg (2010)), which captures horizontal differentiation, and differences in the average educational attainment in occupations using data from the BLS, which captures vertical specialization.

Our parameterized model in the steady state matches well various statistics on asset and income inequality using data from the Survey of Consumer Finance. Examining the determinants of long-run occupational sorting, we find that workers are more likely to choose occupations in which they have highest comparative advantage and that pay high wages. Wealth also matters for occupational sorting - asset-rich individuals are indifferent between employment and non-employment, while asset-poor individuals choose occupations according to their skills and wages. The income and asset distributions in the model exhibit similar 
degrees of dispersion and skeweness as those in the data, with larger concentration in the top percentiles.

We first examine the dynamic response of our model with occupational mobility to a monetary policy shock and compare our model's response to the response from a model without occupational mobility. As in the existing models with uninsurable risk, in response to a contractionary monetary policy shock, consumption declines due to precautionary savings motive, investment declines due to the paradox of thrift, and assets dynamics exhibit BaumolTobin flight to liquidity (see Bayer, Lütticke, Pham-Dao and Tjaden (2019)). The monetary transmission is characterized by the distributional channels, namely earnings-heterogeneity channel, the Fisher effect and the interest rate exposure channel (see Kaplan, Moll and Violante (2018), Auclert (2019)) and the expectational ones (see Galí and Gertler (2007)). Two novel channels arise from occupational reallocation. First, workers reallocate across occupations. Second, some workers choose not to work. If the reallocation channel prevails, the effect of the contractionary shock is tamed through reallocation. Which of the channels prevails depend on the type and the magnitude of the shock, monetary policy stance and other structural characteristics of the economy. Finally, while the model with occupational mobility may tame the contractionary effect of a shock, it generally raises earnings inequality.

The occupational reallocation mechanism is best demonstrated in a setting with a large recessionary shock that hits different occupations unevenly. We therefore apply the model to the recent pandemic recession. The pandemic recession featured a marked reallocation channel through a combination of two kinds of shocks: (1) uneven and persistent occupational or sectoral shocks through the government-mandated shutdowns of non-essential businesses (see, for example, Barrero, Bloom and Davis (2020)), and (2) a large aggregate labor supply shock through infections. The pandemic featured other forces and channels. Our goal is not to account for all the shocks during the pandemic, but to highlight the role of reallocation and its impact on the economy in response to shocks and policies. Furthermore, the shocks that unevenly hit different occupations extend beyond government-mandated stringency measures in the pandemic and are related to the ongoing automation, acceleration in task-encroaching, 
and the disappearance of certain tasks (Autor and Reynolds (2020), Chernoff and Warman $(2020))$.

We introduce occupational shocks in the model by reducing labor demand in certain occupations (retail sales) and raising it in others (healthcare) via shocks to the occupational shares in the production function. As in the models with uninsurable risk, precautionary savings motive induces decline in consumption and the flight to liquidity, and the paradox of thrift rationalizes the fall in investment. ${ }^{1}$ The decline in asset prices, following asset liquidation, reduces wealth inequality by inflicting larger losses for those in the top-percentiles of the wealth distribution. ${ }^{2}$ In the model with occupational mobility, workers reallocate from shrinking to expanding occupations. The increase in income dispersion enhances precautionary savings and, following a large decline in wages, some workers opt out of work. The reallocation and opting out of work exacerbate the recession. The zero-lower-bound policy as compared to the Taylor rule has a dual effect. By equalizing returns on wealth, the zero-lower-bound policy curbs reallocation incentives. On the other hand, it reduces the cost of investment, which in turn raises labor income and demand. Additionally, we show that the extent of the recession as well as the patterns of income inequality largely depend on the type of occupation hit by the shock: a negative shock to a high-wage occupation as compared to a low-wage occupation, worsens the recession and increases the earnings inequality. Finally, a shock to sectoral productivity produces qualitatively similar dynamics; the magnitude of the impact of the sectoral shock depends on the composition of the occupation-specific labor in the shrinking sector.

We introduce the aggregate labor supply shock due to the pandemic infection by augmenting the model with a standard SIR block that features differential infection risks across occupations. In the model, forward-looking optimizing agents respond to the infection risk through occupational mobility and opting out of work. The aggregate labor supply shock induces a fall in labor hours in all occupations, more so in occupations with high risk. Reallocation across occupations is minimal and most of the dynamics is driven by an increased share of workers in non-employment due to the fall in wages and the increase in

1 See earlier work by Aiyagari and Gertler (1991) for impact of flight to liquidity on asset prices.

2 Atkinson, Piketty and Saez (2011) Piketty and Saez (2014), and Scheidel (2020) argue that loss of asset values is one of the reasons behind the decline in inequality at the beginning of the 20th century. 
infection risk. This experiment provides insights into the impact of other aggregate labor supply shocks that trigger decline in labor force participation.

The paper proceeds as follows. Section 2 reviews the related literature. Section 3 presents the model. Section 4 presents analytical results. Section 5 explains data used in the calibration. Section Section 6 shows steady state results and the model's responses to a standard monetary policy shock. Section 7 presents and discusses simulation results under various shocks. Section 8 concludes. Appendices follow.

\section{Related Literature}

The role of sectoral shocks and reallocation for the macroeconomy has a long tradition in economics (Schumpeter (1942), Lilien (1982), Abraham and Katz (1986) and, more recently, Chodorow-Reich and Wieland (2020)). The literature focuses on sectoral reallocation, not occupational mobility. It also generally does not emphasize the link between reallocation and inequality.

Our focus on occupational mobility is motivated by an idea that skills or, more broadly, human capital are closely related to the occupational composition of tasks (Gathmann and Schönberg (2010), Guvenen et al. (2020)). We model occupational choice following a seminal work by Roy (1951), empirical underpinnings of which can be found in Heckman and Honore (1990) and Buera (2006). Recently, Grigsby (2020) estimates a static Roy model to account for the wage stagnation following the financial crisis; Yamaguchi (2012) estimates a dynamic frictionless Roy model with a posited wage function; and Jaimovich, Saporta-Eksten, Siu and Yedid-Levi (2020) studies the role of automation in a general equilibrium Roy model. Our model features a dynamic occupational choice (as in Boskin (1974), Rust (1987) and Keane and Wolpin (1997)) and its interaction with uninsurable risk and wealth. Card, Cardoso, Heining and Kline (2018) applies discrete choice model to studying labour supply. Berger, Herkenhoff and Mongey (2019) discusses an equivalence between nested-logit and nested-CES used in oligopsony - this conceptually parallels the occupational rents/mark-ups which we highlight in our model. 
A paper related to ours is Eeckhout and Sepahsalari (2020). They developed a model with heterogeneous agents, uninsurable risk and directed search that provides a link between inequality and labor search behaviour. In their model, sorting arises from a monotone matching condition, in our shifting probabilities result from a value function optimization. In this respect, the directed search and the Roy approach provide complementary insights. In our model imperfect skill-transferability and the elasticity of substitution across occupations act as frictions to mobility.

A growing literature builds general equilibrium models with heterogeneous uninsurable risk and nominal rigidities. First insights on the different transmission of shocks between the representative agent and the heterogenous agents model came from models featuring liquidity constrained and unconstrained agents (Bilbiie (2008) or Debortoli and Galí (2017)). Our model highlights how inequality can affect also labour supply and occupational reallocation on top and above the consumption decisions. A growing literature has further developed models with heterogenous agents and nominal rigidities (McKay, Nakamura and Steinsson (2016), McKay and Reis (2016), Guerrieri and Lorenzoni (2017), Gornemann, Kuester and Nakajima (2016),Kaplan et al. (2018), Bayer et al. (2019), Ravn and Sterk (2017), Auclert et al. (2019), Auclert and Rognlie (2018), Auclert, Rognlie and Straub (2018), (Auclert, Rognlie and Straub 2020) or Dupor, Karabarbounis, Kudlyak and Mehkari (2018), among others). These papers do not study the role of skill heterogeneity, human capital or occupational choice. Our model endogenizes the cross-sectional variation in income and provides a two-way link between inequality and occupational mobility.

The role of skills for inequality is also studied in Keane and Wolpin (1997) and Huggett, Ventura and Yaron (2011). Early work on the link between inequality and occupational choice include Galor and Zeira (1993) and Banerjee and Newman (1993). The impact of education on wage inequality in an incomplete-market life-cycle model is in Heathcote, Storesletten and Violante (2010). Reallocation channels are featured in Lise and Postel-Vinay (2020), in experimentation models such as Jovanovic (1979) and Antonovics and Golan (2012) and in models with rest unemployment (see Alvarez and Shimer (2011)). They do not endogeneize the shifting probabilities (both across occupations and in and out of employment) and do 
not consider the role of uninsurable risk and the interaction between occupational mobility and inequality.

Our model features jointly the choice of labor hours (intensive), labor participation and of the type of occupation (extensive margin and mobility choice). Chang and Kim (2006) and Chang, Kim, Kwon and Rogerson (2019) embed the choice of heterogenous labour hours in models with uninsurable risk and Heathcote, Perri and Violante (2020) add a non-participation margin.

Our paper is also related to the literature studying the impact of the pandemic shock on the severity of the recession and inequality (Kaplan, Moll and Violante (2020), Bayer, Born, Luetticke and Müller (2020), Eichenbaum, Rebelo and Trabandt (2020a), Krueger, Uhlig and Xie (2020) and Guerrieri, Lorenzoni, Straub and Werning (2020)). Guerrieri et al. (2020) study sectoral reallocation during the pandemic, while our paper examines occupational reallocation. Our application that considers the differential impact of supply and sector-demand shocks relates our paper to Baqaee and Farhi (2020).

\section{Heterogenous Agents Model with Dynamic Occupational Choice and Idiosyncratic Income Risk}

The key novelty of our work is embedding endogenous occupational mobility in a multi-sector multi-occupation Bewley (1980)-Aiyagari (1994) model with liquid and non-liquid assets and sticky prices. In the model, risk-averse infinitely lived households are heterogeneous - they differ by skill. The household's skill-type determines the effective labor units that the household can supply in each occupation. The household can also choose to remain non-employed, receiving a flow value of non-employment. Households' optimization can be summarized as a two-stage problem. In the first stage, households choose whether to work and which occupation to work at by solving a discrete choice problem comparing value functions across all possible choices. We obtain a closed-form solution for the occupational choice probabilities, under the assumption of extreme value type I taste shocks. In equilibrium, the occupational choice probabilities depend on the value functions, which in turn depend on 
wages, wealth and skills. Given the occupational choice, in the second stage, households solve a consumption-saving problem and choose consumption and investment in liquid and nonliquid assets. The cost of liquidating the non-liquid asset impairs households' precautionary saving ability; consequently, any inequality in wages entrenches into wealth inequality.

Aggregate output is a CES bundle of sectoral varieties. The production block features $S$ sectors, each one employing each of the $O$ occupations, according to the sector-specific shares, $\alpha_{s, o}$. Sectoral output is produced by bundling the effective units of labor from all occupations using a sector-specific production function. Each occupation is characterized by its own market clearing condition.

In this section, we describe heterogeneous households and heterogeneous firms problems and define the equilibrium.

\subsection{Consumption-Saving and Occupational Choice}

Households can be employed in one of many different occupations indexed by $o \in\{1, \ldots, O\}$ or non-employed. When we discuss occupational choice, we refer to the choice out of $O+1$ options, where option $O+1$ is non-employment. These options differ by the associated flow values and the taste shocks.

Skill heterogeneity. Households differ in their skills and, hence, efficiency units of labor that they can provide in each occupation. The household's skill-type (hereafter, type) is indexed by $j \in\{1, \ldots, J\}$. There is the time-invariant mass $m_{j}$ of each type $j$. Each type $j$ is characterized by vector $\gamma_{j}$, which describes the efficiency units that the type $j$ can provide in each occupation $o \in\{1, \ldots, O\} . \Gamma$ is the $J \times O$ matrix that stacks the (transposed) vectors for all $J$ types. The matrix captures the way in which household's skill heterogeneity relates to occupations and plays a crucial role in determining the degree of reallocation across occupations. Each matrix element $\gamma_{j}^{o}$ characterizes the comparative advantage of worker of type $j$ in performing the tasks in occupation $o$. The skill-matrix is fixed over time. It is possible to extend the model to allow for the matrix to change in response to persistent occupational shocks.

Non-employment state. The menu of possible household's activity choices includes 
non-employment. In the non-employment state, which encompasses out of the labor force and non-employment, individuals receive the flow value of non-work expressed in real income units, $h$. The flow value of non-work encompasses home-production and self-employment. ${ }^{3}$ The flow value of non-work, $h$, is the same for all household types.

Idiosyncratic productivity risk. At the end of each period $t$, employed and nonemployed households experience idiosyncratic productivity shock $e_{t}$. The shock follows an $n_{e}$-state Markov process with transition matrix $P\left(e_{t+1} \mid e_{t}\right)$ and stationary distribution $\pi(e)$. The shock is independent of the household's skill type or current occupation (or the non-employment state).

Labor income. Real after-tax labor income $\xi_{j, t}^{o}$ of individual of type $j$ at time $t$ in occupation $o$ is a function of efficiency units of type $j$ in occupation $o, \gamma_{j}^{o}$, idiosyncratic productivity state $e_{t}$, real wage in occupation $o w_{t}^{o}$, labor hours $n_{t}^{o}$, and tax rate $\tau_{t}$ :

$$
\xi_{j, t}^{o}=\left(1-\tau_{t}\right) e_{t} w_{t}^{o} \gamma_{j}^{o} n_{t}^{o}
$$

Heterogeneity enters labor income through three components. The first component is the time-invariant efficient labor units supplied by household of type $j$ in occupation $o$. The second component is the occupational wage, which is endogenously determined in the labor market. The third component is the exogenous idiosyncratic productivity shock, common to all heterogeneous agents models with uninsurable risk. In the model, occupational wage is the same in each sector. Therefore, workers are indifferent across sectors, conditional on their occupational choice. This is supported by the empirical evidence that human capital is occupation-specific.

Let $\boldsymbol{\xi}_{j, t}$ denote the $(O+1)$-dimensional vector of the real after-tax labor income of type $j$ individuals in time $t$ in all possible occupations $o \in O$, which consists of elements $\xi_{j, t}^{o}$, and the real after-tax income-equivalent in the non-employed state, $\xi_{j, t}^{O+1}=h$ for all $j \in J$.

Taste shocks. Each period, households draw idiosyncratic occupational-preference shock $\phi_{t}^{o}$ for all $o \in O+1$ (in terms of utility). The taste shock is assumed to be i.i.d. across workers

3 An alternative formulation is the one adopted in Grigsby (2020) who assumes a zero flow value of non-employment, but subtracts a constant opportunity costs from the income in each occupation. 
and occupations and follows a type 1 extreme value distribution, with density $f(\phi)$ and cumulative distribution function $F(\phi)$. The distributional assumptions follow the tradition of discrete choice models and generate a tractable form for the choice probabilities (see McFadden and Zarembka (1974)). The occupation-specific taste shock serves as a smoothing device in discrete choice models (see Rust (1987); Iskhakov, Jørgensen, Rust and Schjerning $(2015))$.

Sequence of decisions. Each period a household of type $j$ decides on the occupational choice or non-employment $o \in\{1, \ldots, O, O+1\}$, their consumption and savings. Hours are equal across occupations $n^{o}=n$ for all $o$ and are chosen by representative heads. The state in period $t$ is $\left(e_{t}, a_{t-1}, b_{t-1}, \phi_{t}\right)$ where $e_{t}$ is the idiosyncratic productivity shock, $a_{t}$ are the illiquid assets, $b_{t}$ are the liquid assets, and $\phi_{t}$ is the $(O+1)$-vector of the taste shocks across all occupations and the non-employment state. Household of type $j$ maximizes the following value function, given the state:

$$
\begin{aligned}
& V_{j}\left(e_{t}, a_{t-1}, b_{t-1}, \phi_{t}\right)=\max _{o_{t}, c_{t}, a_{t}, b_{t}} u\left(c_{t}, n_{t}^{o}\right)+\phi_{t}^{o}+\beta E_{\phi} E_{e} V_{j}\left(e_{t+1}, a_{t}, b_{t}, \boldsymbol{\phi}_{t+\mathbf{1}}\right) \\
& \text { s.t. } \quad c_{t}+a_{t}+b_{t}=\xi_{j, t}^{o}+\left(1+r_{t}^{a}\right) a_{t-1}+\left(1+r_{t}^{b}\right) b_{t-1}-\Phi\left(a_{t}, a_{t-1}\right) \\
& a_{t} \geq 0, \quad b_{t} \geq \underline{b}
\end{aligned}
$$

where $\xi_{j, t}^{o}$ is the income in occupation $o, r_{t}^{a}$ and $r_{t}^{b}$ are the interest rates on illiquid and liquid assets, respectively, $\Phi($.$) is the convex portfolio adjustment costs defined below, and$ $\beta$ is the time discount factor. The instantaneous utility takes the standard separable form $u(c, n)=\frac{c^{1-\sigma}}{1-\sigma}-\frac{n^{1+\rho}}{1+\rho}$. For liquid assets, equation $b_{t} \geq \underline{b}$ acts as a borrowing constraint. The value function depends on the idiosyncratic income shock, $e_{t}$, through $\xi_{j, t}^{o}$.

The household's problem can be broken into two stages and solved backwards as follows. First, households make their consumption-saving decision, conditional on the occupation choice at time $t$ and taking into account all possible occupations that they can work at in the future. Second, after substituting the consumption-saving policy functions for each occupation into the value functions, the household determines the probabilities of working in each occupation by comparing value functions across occupations.

Consumption-saving decision. Consider consumption-saving decision of a household 
that optimally chooses occupation $o$. Conditional on occupational choice $o$, each household of type $j$ in period $t$ chooses consumption, $c_{t}$, savings in liquid, $b_{t}$, and illiquid, $a_{t}$, assets to maximize the following value function:

$$
\begin{aligned}
& V_{j}^{o}\left(e_{t}, a_{t-1}, b_{t-1}\right)=\max _{c_{t}, a_{t}, b_{t}} u\left(c_{t}, n_{t}\right)+\beta E_{\phi} E_{e} V_{j}\left(e_{t+1}, a_{t}, b_{t}, \phi_{t+1}\right) \\
& \text { s.t. } \quad c_{t}+a_{t}+b_{t}=\xi_{j, t}^{o}+\left(1+r_{t}^{a}\right) a_{t-1}+\left(1+r_{t}^{b}\right) b_{t-1}-\Phi\left(a_{t}, a_{t-1}\right) \\
& \quad a_{t} \geq 0, \quad b_{t} \geq \underline{b}
\end{aligned}
$$

where $V_{j}^{o}\left(e_{t}, a_{t-1}, b_{t-1}\right)$ is the value function in time $t$ of type $j$ conditional on occupation $o$ and $\phi_{t}^{o}$ evaluated at 0 .

The portfolio adjustment costs take the following functional form:

$$
\Phi\left(a_{t}, a_{t-1}\right)=\frac{\chi_{1}}{\chi_{2}}\left|\frac{a_{t}-\left(1-r_{t}^{a}\right) a_{t-1}}{\left(1+r_{t}^{a}\right) a_{t-1}+\chi_{0}}\right|^{\chi_{2}}\left[\left(1+r_{t}^{a}\right) a_{t-1}+\chi_{0}\right]
$$

with $\chi_{0}>0, \chi_{1}>0$ and $\chi_{2}>1$. Note that $\Phi\left(a_{t}, a_{t-1}\right)$ is bounded, differentiable, and convex in both arguments. Consumption-savings and portfolio decisions follow the standard Euler conditions (shown in Appendix B).

Labor hours are chosen by the family as a whole and are determined through the intratemporal first order condition:

$$
\varphi n_{t}^{\rho}=\sum_{o=1}^{O} \sum_{j=1}^{J} m_{j} \int u_{c}\left(e_{t}, a_{t-1}, b_{t-1}, o_{t}\right) \theta_{j}\left(o \mid e_{t}, a_{t-1}, b_{t-1}\right) \frac{\partial \xi_{j, t}^{o}}{\partial n_{t}^{o}} d D_{j}\left(e_{t}, a_{t-1}, b_{t-1}\right)
$$

where $\theta_{j}\left(o \mid e_{t}, a_{t-1}, b_{t-1}\right)$ are optimal probabilities of each occupation (see derivation below).

The solution to the optimization problem is a collection of type- and occupation-specific policy functions $c_{j}^{o}\left(e_{t}, a_{t-1}, b_{t-1}\right), a_{j}^{o}\left(e_{t}, a_{t-1}, b_{t-1}\right)$ and $b_{j}^{o}\left(e_{t}, a_{t-1}, b_{t-1}\right)$ that depend on the path $\left\{r_{s}^{a}, r_{s}^{b}, \tau_{s}\right\}_{s>t}$, taken as given by households.

Occupational decision. Following the tradition of random discrete choice models, we model occupational choice as a comparison of the value functions, which is an inherently 
dynamic problem. Household of type $j$ chooses occupation $o$ by comparing value functions from each choice, evaluated at the optimal consumption-saving policies:

$$
o=\operatorname{argmax}_{[1, \ldots \ldots, O, O+1]}\left[\tilde{V}_{j}^{o}+\phi_{t}^{o}\right]
$$

where $\tilde{V}_{j}^{o}$ is the value function $V_{j}^{o}\left(e_{t}, a_{t-1}, b_{t-1}\right)$ evaluated at the optimal consumption-saving policy $c_{j}^{o}\left(e_{t}, a_{t-1}, b_{t-1}\right), a_{j}^{o}\left(e_{t}, a_{t-1}, b_{t-1}\right)$ and $b_{j}^{o}\left(e_{t}, a_{t-1}, b_{t-1}\right)$. We skip the dependence of the value function on the state for notational convenience. Note that the taste shock, $\phi_{t}^{o}$, only affects preferences for occupation and does not influence the consumption-saving decision.

The solution $o$ to the occupational choice problem (6) satisfies

$$
F\left(\tilde{V}_{j}^{o}+\phi_{t}^{o} \geq \tilde{V}_{j}^{o^{\prime}}+\phi_{t}^{o^{\prime}}\right) \forall o^{\prime} \neq o \in O+1
$$

where $F($.$) is the cumulative density of the taste shock.$

Taking expectation with respect to the current period taste shocks of the household value function in (2) and evaluating at the optimal consumption-saving choice yields

$$
E_{\phi} \tilde{V}_{j}\left(e_{t+1}, a_{t}, b_{t}, \phi_{t+\mathbf{1}}\right)=E_{\phi} \max _{o t}\left[\tilde{V}_{j}^{o}\left(e_{t}, a_{t-1}, b_{t-1}\right)+\phi_{t}^{o}\right]=\ln \left(\sum_{o_{t}} \exp \left(\tilde{V}_{j}^{o}\left(e_{t}, a_{t-1}, b_{t-1}\right)\right)\right)
$$

where the last equality follows from the properties of the Gumbel distribution.

Combining (6) and (8) yields the following closed-form solution for the occupational choice probabilities:

$$
\theta_{j}\left(o \mid e_{t}, a_{t-1}, b_{t-1}\right)=\frac{\exp \left(\tilde{V}_{j}^{o}\left(e_{t}, a_{t-1}, b_{t-1}\right)\right)}{\sum_{o} \exp \left(\tilde{V}_{j}^{o}\left(e_{t}, a_{t-1}, b_{t-1}\right)\right)} .
$$

Equation 9 shows that the probabilities of moving among occupations and the non-work state depends on the households' value functions. This implies that the wage distribution, the wealth accumulation and the idiosyncratic income shocks have an impact on occupational mobility. We solve the two-stage optimization problem numerically through a guess-and-verify procedure described in Appendix B. 
Household aggregates. We obtain the aggregate policy functions for consumption and asset holdings by integrating occupation-specific policy functions weighted by occupation choice probabilities over the measure of households in state $e_{t}$ that own assets in sets $A_{-}$and $B_{-}$at the start of date $t$, which is given by $D\left(e_{t}, A_{-}, B_{-},\right)=\operatorname{Pr}\left(e=e_{t}, a_{t-1} \in A_{-}, b_{t-1} \in B_{-}\right)$, and aggregating across all occupations $o \in O+1$ and across all household types $j \in J$.

The aggregate policy functions for households for every period $i \geq t$ are:

$$
\begin{aligned}
& \mathcal{A}_{t}\left(r_{i}^{a}, r_{i}^{b}, \tau_{i}, N_{i}\right)=\sum_{j=1}^{J} m_{j} \sum_{o=1}^{O+1}\left(\int a_{j}^{o}\left(e_{t}, a_{t-1}, b_{t-1}\right) \theta_{j}\left(o \mid e_{t}, a_{t-1}, b_{t-1}\right) d D_{j}\left(e_{t}, a_{t-1}, b_{t-1}\right)\right) \\
& \mathcal{B}_{t}\left(r_{i}^{a}, r_{i}^{b}, \tau_{i}, N_{i}\right)=\sum_{j=1}^{J} m_{j} \sum_{o=1}^{O+1}\left(\int b_{j}^{o}\left(e_{t}, a_{t-1}, b_{t-1}\right) \theta_{j}\left(o \mid e_{t}, a_{t-1}, b_{t-1}\right) d D_{j}\left(e_{t}, a_{t-1}, b_{t-1}\right)\right) \\
& \mathcal{C}_{t}\left(r_{i}^{a}, r_{i}^{b}, \tau_{i}, N_{i}\right)=\sum_{j=1}^{J} m_{j} \sum_{o=1}^{O+1}\left(\int c_{j}^{o}\left(e_{t}, a_{t-1}, b_{t-1}\right) \theta_{j}\left(o \mid e_{t}, a_{t-1}, b_{t-1}\right) d D_{j}\left(e_{t}, a_{t-1}, b_{t-1}\right)\right)
\end{aligned}
$$

where $N_{i}$ is total hours (in employment and non-employment).

Total labor hours supplied in each occupation $o$ is given by:

$$
N_{t}^{o}=n_{t}^{o} \zeta_{t}^{o} \sum_{j=1}^{J} m_{j} \int \theta_{j}\left(o \mid e_{t}, a_{t-1}, b_{t-1}\right) d D_{j}\left(e_{t}, a_{t-1}, b_{t-1}\right)
$$

where $n_{t}^{o}$ is the labor hours per occupation. $\zeta$ is the coefficient that determines the decrease in labor supply due to an increase in the number of infected people in response to an infection shock, i.e. $\zeta_{t}^{o}=1-\mathcal{I}_{t} \cdot \vartheta^{o}$, where $\mathcal{I}_{t}$ is the number of infected people and $\vartheta_{o}$ is the occupation-specific constant.

The total effective labor supply in occupation $o$ is given by the efficiency-units-weighted and idiosyncratic-shock-weighted employment in each occupation:

$$
L_{t}^{o, \text { Supply }}=n_{t}^{o} \zeta_{t}^{o} \sum_{j=1}^{J} m_{j} \gamma_{j}^{o} \int e_{t} \theta_{j}\left(o \mid e_{t}, a_{t-1}, b_{t-1}\right) d D_{j}\left(e_{t}, a_{t-1}, b_{t-1}\right)
$$




\subsection{Heterogeneous Firms: Labor Demand, Capital Demand, and Pricing Decisions}

There is a set of sectors (i.e., industries) $s \in 1, \ldots, S$, each producing sector-specific (i.e., variety) output $y_{s, t}$ using a sector-specific production function. A representative competitive firm aggregates different varieties from all sectors in the economy through a CES aggregate consumption bundle:

$$
Y_{t}=\left(\sum_{s=1}^{S} f_{s}^{\frac{1}{\eta}} y_{s, t}^{\frac{\eta-1}{\eta}}\right)^{\frac{\eta}{\eta-1}},
$$

where $\eta$ is the elasticity of substitution across varieties and $f_{s}$ are the sector weights that capture the size of each sector in the economy. This implies that optimal demand equation

for each variety is given by $p_{s, t}=\left(f_{s} \frac{Y_{t}}{y_{s, t}}\right)^{\frac{1}{\eta}} p_{t}$, where $p_{t}$ is the aggregate price index and is normalized to 1 in the steady state.

Each sector employs a sector-specific combination of occupations, in terms of occupationspecific effective labor hours $l_{s, o, t}$, with different shares $\alpha_{s, o}$ and elasticity of substitution $\sigma_{s}$. Total labor demand by sector $s$ is

$$
L_{s, t}=\left(\sum_{o=1}^{O} \alpha_{s, o} l_{s, o, t}^{\sigma_{s}}\right)^{\frac{1}{\sigma_{s}}}
$$

The elasticity of substitution across occupations, $\frac{1}{\sigma_{s}}$, plays a crucial role in determining the extent of reallocation across occupations as we show in the analytical results in Section 4. It also determines the elasticity of substitution of labor demand with respect to wages; hence, it captures the degree of occupational specialization.

Sectors produce output by combining total labor input and capital using a nested CES production function:

$$
y_{s, t}=z_{s, t} k_{s, t-1}^{\nu_{s}} L_{s, t}^{1-\nu_{s}}
$$

where $y_{s, t}$ is the variety, $z_{s, t}$ is sector total factor productivity and $\nu_{s}$ is the capital share.

Firms in each sector $s$ choose labor demand, $l_{s, o, t}$, for each occupation $o \in O$, capital 
demand, $k_{s, t}$, and investment, $I_{s, t}$, to maximize the sum of future discounted real profits, which recursively reads as follows:

$$
\begin{aligned}
J_{s, t}\left(k_{s, t-1}\right)=\max _{p_{s, t}, k_{s, t}, I_{s, t}, l_{s, o, t}}\left\{\frac{p_{s, t}}{p_{t}} y_{s, t}-\sum_{o=1}^{O} w_{t}^{o} l_{s, o, t}-I_{s, t}-\frac{1}{2 \varkappa \varepsilon_{I}}\left(\frac{k_{s, t}-k_{s, t-1}}{k_{s, t-1}}\right)^{2} k_{s, t-1}\right. \\
\left.-\frac{\eta}{2 \kappa} \ln \left(1+\pi_{s, t}\right)^{2} Y_{t}+\frac{J_{t+1}\left(k_{s, t}\right)}{1+r_{t+1}}\right\} \\
\text { s.t. } \quad k_{s, t}=(1-\delta) k_{s, t-1}+I_{s, t} \\
p_{s, t}=\left(f_{s} \frac{Y_{t}}{y_{s, t}}\right)^{\frac{1}{\eta}} p_{t} \\
y_{s, t}=z_{s, t} k_{s, t-1}^{\nu} L_{s, t}^{1-\nu}
\end{aligned}
$$

where equation (20) is the capital accumulation equation, $\delta$ is the depreciation rate of capital, and $\frac{\eta}{2 \kappa} \ln \left(1+\pi_{s, t}\right)^{2} Y_{t}$ is the quadratic price adjustment cost. Firms face quadratic adjustment costs on physical capital, with a standard functional form of $\frac{1}{2 \varkappa \varepsilon_{I}}\left(\frac{k_{s, t}-k_{s, t-1}}{k_{s, t-1}}\right)^{2} k_{s, t-1}$, which leads to a variable price of capital.

The first order conditions for labor demand is:

$$
l_{s, o, t}=\left(\frac{p_{s, t}\left(1-\nu_{s}\right) \alpha_{s, o}}{\mu_{p} p_{t} w_{t}^{o}}\right)^{\frac{1}{1-\sigma_{s}}}\left(z_{s, t} k_{s, t-1}^{\nu_{s}}\right)^{\frac{\sigma_{s}}{(1-\nu)\left(1-\sigma_{s}\right)}} y_{s, t}^{\frac{\sigma_{s}-1+\nu_{s}}{\left(1-\nu_{s}\right)\left(\sigma_{s}-1\right)}}
$$

where $\mu_{p}=\frac{\eta}{\eta-1}$. Defining $q_{s, t}$ as the Lagrange multiplier on the capital accumulation in sector $s$ and, hence, as the shadow price of capital, the firm's first order condition for the capital stock in sector $s$ is:

$$
\begin{aligned}
\left(1+r_{t+1}\right) q_{s, t} & =\nu_{s} z_{s, t+1}\left(\frac{L_{s, t+1}}{k_{s, t}}\right)^{1-\nu_{s}} m c_{s, t+1}- \\
& -\left[\frac{k_{s, t+1}}{k_{s, t}}-(1-\delta)+\frac{1}{2 \varkappa \varepsilon_{I}}\left(\frac{k_{s, t+1}-k_{s, t}}{k_{s, t}}\right)^{2}+\frac{k_{s, t+1}}{k_{s, t}} q_{s, t+1}\right]
\end{aligned}
$$


where $m c_{s, t+1}$ is the Lagrange multiplier on the production constraint and represents real marginal cost. The first order condition with respect to investment is

$$
q_{s, t}=1+\frac{1}{\varkappa \varepsilon_{I}}\left(\frac{k_{s, t}-k_{s, t-1}}{k_{s, t-1}}\right)
$$

The first order condition with respect to prices leads to the sector-specific Phillips curve:

$$
\log \left(1+\pi_{s, t}\right)=\kappa\left(\frac{p_{s, t}}{p_{t}}\right)^{-\eta}\left(m c_{s, t}-\frac{1}{\mu_{p}} \frac{p_{s, t}}{p_{t}}\right)+\frac{Y_{t+1}}{Y_{t}} \log \left(1+\pi_{s, t+1}\right) \frac{1}{1+r_{t+1}}
$$

Note that our model features heterogeneous households and heterogeneous firms. Since firms in each sector use a different production function, they also choose different capital and investment inputs and different price of capital, $q_{s, t}$, and, hence, different equity price and dividends. Aggregation is obtained by summing profits and inputs across different sectors.

\subsection{Asset Returns}

Let $r_{t}$ denote the ex-post return on government bonds. Let $v_{s, t}$ be the ex-dividend price of equity and $d_{s, t+1}$ be the dividend in sector $s$. The real return on equity is $\frac{d_{s, t+1}+v_{s, t+1}}{v_{s, t}}$. The no-arbitrage condition for each sector $s$ is: $v_{s, t}=\frac{d_{s, t+1}+v_{s, t+1}}{1+r_{t+1}}$. The combined return on illiquid assets is:

$$
\left(1+r_{t}^{a}\right)=\sum_{s=1}^{S}\left(\frac{v_{s, t}}{\mathcal{A}_{t}}\right) \frac{d_{s, t}+v_{s, t}}{v_{s, t-1}}+\frac{B^{g}-\mathcal{B}_{t}}{\mathcal{A}_{t}}\left(1+r_{t}\right)
$$

Government does not issue new debt and pays interest on the constant level $B^{g}$.

To obtain the return on liquid assets, we introduce a representative competitive financial intermediary in the model which transforms illiquid into liquid assets through a technology that operates at a proportional cost $\psi$. Arbitrage between the two assets coupled with a zero profit condition on the intermediary leads to the following expression for the return on liquid assets: $r_{t}^{b}=r_{t}-\psi$. 


\subsection{Monetary and Fiscal Policy}

Fiscal policy $G_{t}$ follows a balanced-budget policy:

$$
\tau_{t} \sum_{o=1}^{O} \sum_{s=1}^{S} w_{t}^{o} l_{s, o, t}=r_{t} B^{g}+G_{t}
$$

Monetary policy follows a simple Taylor-type rule:

$$
i_{t}=r_{t}^{*}+\phi_{\pi} \pi_{t}+\phi_{y}\left(Y_{t}-Y_{s s}\right)
$$

where $i_{t}$ is the monetary policy interest rate, $\phi_{\pi}$ is the weight on inflation $\pi_{t}, \phi_{y}$ is the weight on output gap, $r_{t}$ is the real interest rate, $r_{t}^{*}$ is the natural interest rate, which is equal to the real interest rate in the steady state, and $1+r_{t}=\frac{1+i_{t-1}}{1+\pi_{t}}$.

Stabilization policy, by responding to the dynamics of macroeconomic variables, can alter the role of shocks and other channels in the model. Hence, to fully assess the role of occupational reallocation for the macroeconomic dynamics, the endogenous response of the policy stance shall be taken into account.

\subsection{SIR Block}

We use the standard SIR model. ${ }^{4}$ There are three possible states in which each individual can be: susceptible $(\mathcal{S})$, infected $(\mathcal{I})$, and recovered $(\mathcal{R})$. The disease spreads when susceptible and infected get in contact with each other. The number of susceptible decreases because they get infected. The number of infected declines as they recover. Recovered people are immune to the disease. The only salient modification is the inclusion of occupation-specific risks, with

4 See, for example, Heathcote et al. (2020). 
face-to-face occupations featuring higher infection risk. The mathematical representation of the model is as follows:

$$
\begin{aligned}
\mathcal{S}_{t+1} & =\mathcal{S}_{t}-\beta_{\text {sir }} \frac{\mathcal{S}_{t} I_{t}}{\mathcal{N}_{t}}-\varepsilon_{\text {pandemic }}, \quad \mathcal{S}_{0}=1 \\
\mathcal{I}_{t+1} & =\mathcal{I}_{t}+\beta_{\text {sir }} \frac{\mathcal{S}_{t} \mathcal{I}_{t}}{\mathcal{N}_{t}}-\gamma_{\text {sir }} \mathcal{I}_{t}+\varepsilon_{\text {pandemic }}, \quad \mathcal{I}_{0}=0 \\
\mathcal{R}_{t+1} & =\mathcal{R}_{t}+\gamma_{\text {sir }} \mathcal{I}_{t}, \quad \mathcal{R}_{0}=0 \\
\mathcal{N}_{t} & =\mathcal{S}_{t}+\mathcal{I}_{t}+\mathcal{R}_{t}
\end{aligned}
$$

where $\beta_{\text {sir }}$ is the contact and infection rate, $\gamma_{\text {sir }}$ is the probability of recovery within the

unit of time, and $\frac{\beta_{s i r}}{\gamma_{s i r}}$ is the average number of contacts the infected person has during the infectious period.

The SIR block connects to the HANK model through the aforementioned decrease in the supply of labor hours - via $\zeta_{t}^{o}$ as described in eq. (14). Our model allows accounting for the households behavioural response to the infection shocks. The model features an infection risk that differs by occupation. In response to the infection shock, households adjust their consumption-saving and occupational decisions, which in turn affects the pace of infection spread..$^{5}$

\subsection{Market Clearing: Labor, Goods and Asset Markets}

Wages are determined in equilibrium by equating labor supply and demand for each occupation, hence:

$$
\underbrace{L_{t}^{o, \text { Demand }}=\sum_{s=1}^{S} l_{s, o, t}}_{\text {Demand }}=\underbrace{n_{t}^{o} \zeta_{t}^{o} \sum_{j=1}^{J} m_{j} \int e_{t} \theta_{j}\left(o \mid e_{t}, a_{t-1}, b_{t-1}\right) d D_{j}\left(e_{t}, a_{t-1}, b_{t-1}\right)=L_{t}^{o, \text { Supply }}}_{\text {Supply }}
$$

5 See Boppart, Harmenberg, Hassler, Krusell and Olsson (2020) on the time use choice during pandemics, Farboodi, Jarosch and Shimer (2020), Alfaro, Faia, Lamersdorf and Saidi (2020), and Engle, Keppo, Kudlyak, Smith and Wilson (2020) on the importance of accounting for the behavioural response in in the pandemic path, Barry (2020) and Barro, Ursúa and Weng (2020) on evidence on absenteeism and low participation in pandemics. 
Market clearing takes place at the occupation level. As noted earlier, workers are indifferent among sectors, hence, there is full mobility and wage equalization across sectors.

Aggregate good supply is equal to aggregate good demand, hence:

$$
Y_{t}+h L_{t}^{O+1}=\mathcal{C}_{t}+G_{t}+I_{t}+\psi \mathcal{B}_{t}+\Phi_{t}
$$

where $\psi \mathcal{B}_{t}$ is the resource cost from liquidating assets, $L_{t}^{O+1}$ is the number of individuals in the non-employment state, and where all variables above are aggregates obtained through the joint distribution, $D_{t}$, defined above.

Finally, asset markets clearing implies

$$
\mathcal{A}_{t}+\mathcal{B}_{t}=\sum_{s}^{S} v_{s, t}+B^{g}
$$

where again aggregation is obtained through the joint distribution $D_{t}$.

\subsection{Equilibrium}

\section{Definition 1: Competitive Equilibrium}

A Competitive Equilibrium of the economy satisfies the following definition:

- The sequence $\left[c_{t}, a_{t}, b_{t}\right]_{t=0}^{\infty}$ solves households' consumption-saving decision in eq. (3), given the distribution of idiosyncratic shocks, $P\left(e_{t+1} \mid e_{t}\right)$ and the sequence of prices $r_{t}^{a}, r_{t}^{b}, r_{t}, \boldsymbol{w}_{t}$

- The sequence of probabilities $\left[\theta_{t}\right]_{t=0}^{\infty}$ solves households' occupational choice problem in (6).

- Aggregate assets holdings and consumption of the households are equal to the product of the individual optimal functions and the distribution of households across occupations and assets.

- Firms choose labor demand for each occupation, $l_{s, o, t}$, and capital inputs, $k_{s, t}$ to solve discounted profits optimization, given in section 3.2. 
- The fraction of the population that is infected, susceptible or recovered is determined by the system of difference equations in eq. (30).

- Market clearing and the aggregate resource constraints are satisfied.

- Monetary policy determines the short term interest rate according to eq. (28) and fiscal policy follows a balanced budget rule as in eq. (27).

\section{Analytical Results}

In this section, we provide some analytical results that highlight the role of technological parameters (sectoral output shares, sectoral occupational shares, job specialization) on the extent of reallocation, on job rents and on aggregate output. Our focus here is mostly on how the technological parameters affect reallocation through cross-sectional and overall changes in labor demand. For analytical tractability the focus here is on long run results.

\section{Proposition 1. Determinants of Allocation of Labor across Occupations and}

Sectors. Consider an economy in which sectoral output is given by $y_{s, t}=z_{s, t} K_{s, t-1}^{\nu_{s}} L_{s, t}^{1-\nu_{s}}$, sectoral prices follow $p_{s, t}=\left(f_{s} \frac{Y_{t}}{y_{s, t}}\right)^{\frac{1}{\eta}} p_{t}$, labor aggregation across occupations is given by $L_{s, t}=\left(\sum_{o=1}^{O} \alpha_{s, o} l_{s, o, t}^{\sigma_{s}}\right)^{\frac{1}{\sigma_{s}}}$ and aggregate labor input demand is given by Equation (A.10). For given wage distribution, the allocation of effective units of labor across occupations depends on the following primitives: $\alpha_{s, o}$ across all $s$ and $o$ and $\sigma_{s}$. The allocation of labor shares across sectors depend on the following primitives: $\alpha_{s, o}, \sigma_{s}, \nu_{s}, z_{s, t}$ and $f_{s}$ across all $s$.

Proof. See Appendix A.

The allocation of labor shares is determined by labor demand and its primitives. Those are the weights in the production function, $\alpha_{s, o}, \nu_{s}$ and $f_{s}$, the sectoral productivity, $z_{s, t}$, and the job substitution of specialization, $\sigma_{s}$. More specialized jobs reduce the elasticity of labor demand to wage. In Appendix A labor shares across occupations are shown to depend also on the wage distribution, with the latter being affected by labor supply primitives, namely $\Gamma$. Hence, the result for occupational labor shares in Proposition 1 is partial equilibrium holding for a given labor supply. 
Proposition 2. Occupational Specialization and Rents. Consider the economy described Proposition 1. The elasticity of labor demand with respect to wages in occupation $o$ is $\varepsilon_{l, w}^{o}=\frac{1}{\sigma_{s}-1}\left(1-\frac{l_{s, o} w^{o}}{\sum_{o^{\prime}=1}^{O} l_{s, o^{\prime}} w^{o^{\prime}}}\right)$ and declines with $\sigma_{s}\left(\varepsilon_{l, w}^{o}=\frac{1}{\sigma_{s}-1}\right.$ with infinite number of occupations) and the mark-up or rent extracted by each occupation are given by the inverse of $\mu_{w}=\frac{1-\frac{l_{s, o w}}{\sum_{o^{\prime}=1}^{o} l_{s, o^{\prime}} w_{o}^{\prime}}}{\sigma_{s}-\frac{l_{s, o} w_{o}}{\sum_{o^{\prime}=1}^{O} l_{s, o^{\prime}} w_{o}^{\prime}}}$ (with infinite number of occupations $\mu_{w}=\frac{\varepsilon_{l, w}}{\varepsilon_{l, w}+1}=\frac{1}{\sigma_{s}}$ ).

Proof. See Appendix A.

The above proposition highlights the role of job substitutability, $\frac{1}{\sigma}$, on reallocation as driven by cross-sectional changes in labor demand. Higher $\sigma$ increases substitutability of occupations for firms and the elasticity of labor demand to wages. This is the sense in which lower substitability represents a mobility cost (see Kennan and Walker (2011)). This implies that any cross-sectional variation in wages triggers less cross-sectional changes in labor demand, hence less reallocation (see also our simulation results in section 7.1). It also implies that, since job specialization decreases, job rents or mark-up decrease too.

Proposition 3. The Role of Reallocation for Output. In the framework described in Proposition 1, given the normalization $\sum_{o=1}^{O} \alpha_{s, o}=1 \forall s$, a rise in $\sigma$, raises aggregate output.

Proof. See Appendix A.

The results from Proposition 3 target overall changes in labor demand following changes in $\sigma$. Changes in the latter also modify the capital-labor complemetarities or substitutability, and through the latter changes in aggregate labor demand.

\section{Model Parametrization and Solution Method}

\subsection{Skills, Occupations and Skills Distribution}

A key element of the reallocation channel is the matrix $\Gamma$ of skills distribution. Each vector of this matrix provides the set of talents that each household type $J$ has for each occupation. Hence, each element of the matrix, $\gamma_{j}^{o}$, provides the comparative advantage, in terms of 
efficiency units of labor, of each household $j$ for occupation $o$. O-NET data are employed to calibrate this matrix, as it is the best suited to quantify the concept of task-specific human capital (Gathmann and Schönberg (2010)). First, to reduce the curse of dimensionality the 3-digit detailed occupations are grouped into 8 with similar job requirements using k-means clustering. Second, the entries of the matrix $\Gamma$ are filled using the skill-requirements vectors provided in O-NET.

Specifically, first occupations are clustered using O-Net information on the importance of detailed skill, ability and knowledge requirements for 968 unique occupations. Each detailed requirement is ranked by its importance on a scale from 0 to $7 .{ }^{6} \mathrm{~A}$ k-means clustering algorithm is used to identify clusters of 3-digit occupations with similar requirements. Mathematically the k-mean algorithm can be summarized as follows. Let $M$ be distinct elements in the vector of job requirements reported by O-Net. Let $G$ denote a set of detailed occupations in O-Net, each characterized by the M-dimensional vector of requirements $\mathbf{h}_{g}$. Given the set of observations $\left(\mathbf{h}_{1}, \mathbf{h}_{2}, \ldots, \mathbf{h}_{G}\right)$, k-means clustering aims to partition the $\mathrm{G}$ observations into $k(\leq G)$ sets $\mathbf{O}=\left(O_{1}, O_{2}, \ldots, O_{k}\right)$ so as to minimize the within-cluster sum of squares (i.e. variance). Formally, the objective is to find:

$$
\underset{\mathbf{O}}{\arg \min } \sum_{i=1}^{k} \sum_{\mathbf{h} \in O_{i}}\left\|\mathbf{h}-\mathbf{m}_{i}\right\|^{2}
$$

where $\mathbf{m}_{i}$ is the mean of points in $S_{i} . k$ is set to 8 . The resulting 8 occupational clusters are summarised as follows: (1) Manual trade occupations, (2) Management and supervisory occupations, (3) Machine operators, (4) Engineering occupations, (5) Healthcare and community occupations, (6) Personal services, (7) Technical-support occupations, and (8) Office and administrative support.

Second, the entries of the $\Gamma$ matrix are filled with a comparative advantage index constructed from O-NET skill-requirements. Specifically, the number of household skill-types is set equal to the number of occupations and their related required skills. Each household $j$ holds an absolute advantage for the occupation along the diagonal. Next, a measure of skill-

6 For example, O-Net contains information on 52 different elements within abilities - such as "Problem Sensitivity", "Mathematical Reasoning" or "Manual Dexterity". Skill requirements are "Management of Financial Resources", "Social Perceptiveness" or "Complex Problem Solving" etc. 
transferability is constructed as the Euclidean distance between skill of household $j$ (required in occupation $j=o$ ) and skill required in occupation $o^{\prime}$. In the data the skill distance between occupational clusters $o$ and $o^{\prime}$ is the sum of the weighted (by the employment shares in 2019) absolute difference between the elements of $H_{o}$ and $H_{o^{\prime}}$ :

$$
\gamma_{j}^{o}=\sum_{m}^{M} \operatorname{abs}\left|h_{m}^{j}-h_{m}^{o}\right|
$$

This implies that the diagonal entries are the smallest. ${ }^{7}$ Next, to translate the Euclidean distance into a comparative advantage, we re-normalize every row so that the diagonal entries become all ones. This implies that in the final matrix the higher the entry value, the highest is the household comparative advantage for that specific occupation. The characterization done so far captures the concept of horizontal or core-task specialization. In the data however occupations are also hierarchical. To capture also vertical specialization, each entry is multiplied by the share of occupations in cluster $o$ with the same or higher educational attainment. The latter is computed as the mode of educational attainment for all occupations in the cluster using the 2018 BLS data and considering three levels: (1) less than college, (2) college, and (3) more than college. While the above procedure is used to calibrated the baseline matrix, our simulations also consider alternatives to that. This is done both for robustness reasons and also to assess the role of counterfactual skill-distribution on the reallocation channel. Our matrix $\Gamma$ in the baseline calibration looks as following:

Table 1: Skill-distribution $\Gamma$ matrix. Each row represents one type of households. Each column represents skills that different types of households have. The higher the entry in the matrix, the more skilled is the type for that occupation. Note that the diagonal has been normalized to one so as to make all other entries comparable in relative terms.

\begin{tabular}{|c|c|c|c|c|c|c|c|c|}
\hline Type of households & Occ. 1 & Occ. 2 & Occ. 3 & Occ. 4 & Occ. 5 & Occ. 6 & Occ. 7 & Occ. 8 \\
\hline Type 1 & 1 & 0.34 & 0.26 & 0.33 & 0.38 & 0.54 & 0.19 & 0.21 \\
\hline Type 2 & 0.022 & 1 & 0.019 & 0.27 & 0.57 & 0.12 & 0.029 & 0.097 \\
\hline Type 3 & 0.38 & 0.32 & 1 & 0.28 & 0.34 & 0.48 & 0.35 & 0.24 \\
\hline Type 4 & 0.018 & 0.59 & 0.014 & 1 & 0.45 & 0.13 & 0.017 & 0.07 \\
\hline Type 5 & 0.037 & 0.58 & 0.03 & 0.27 & 1 & 0.25 & 0.038 & 0.12 \\
\hline Type 6 & 0.14 & 0.57 & 0.11 & 0.49 & 0.58 & 1 & 0.12 & 0.22 \\
\hline Type 7 & 0.18 & 0.46 & 0.23 & 0.32 & 0.42 & 0.45 & 1 & 0.35 \\
\hline Type 8 & 0.083 & 0.68 & 0.085 & 0.42 & 0.42 & 0.37 & 0.14 & 1 \\
\hline
\end{tabular}

7 Note that the entries are never zeros: since those are grouped occupations the set of skills is an average across all the occupations in the cluster. 
At last, in the baseline parametrization, the shares of households with skill $j$ is distributed uniformly, i.e., $\mu_{j}=1 / J=1 / 8$ for all $j \in J$.

\subsection{Sectors and Production Function}

Industries are aggregated into 8 broad NACE sectors. The weights on the sectoral output in the representative consumption bundle, $f_{s}$, are set according to the share of sectoral output in the total output using data from KLEMS. Their values are in Table 2. The sectoral capital and labor shares are also obtained from KLEMS using the long-run averages from 1987 - 2015. Table 8 in the Appendix provides the list of sectors and their capital and labor shares. In the model capital and labor shares are used to calibrate the parameter $\nu_{s}$. In the one-sector model $\nu_{s}$ is calibrated so as to deliver a capital share of 0.40 . The latter is obtained from the average of the sectoral shares weighted by $f_{s}$. The baseline $\sigma_{s}$ is set to 0.2 for all $s$. The parameter is then varied in the simulations to assess the impact of job specialization on reallocation. The $\alpha_{s}$ shares are calibrated as follows. Production, $y_{s, t}=K_{s, t}^{\nu_{s}} L_{s, t}^{1-\nu_{s}}$, and aggregate labor demand, $L_{s, t}=\left(\sum_{o=1}^{O} \alpha_{s, o} l_{s, o, t}^{\sigma_{s}}\right)^{\frac{1}{\sigma_{s}}}$, are substituted in the firms' first order conditions for labor:

$$
\left(1-\nu_{s}\right) K_{s, t}^{\nu_{s}} L_{s, t}^{-\nu_{s}} \alpha_{s, o} \frac{1}{\sigma_{s}}\left(\sum_{o=1}^{O} \alpha_{s, o} l_{s, o, t}^{\sigma_{s}}\right)^{\frac{1}{\sigma_{s}}-1} \sigma_{s} l_{s, o, t}^{\sigma_{s}-1}=w_{o}
$$

Then taking the ratios, $\frac{\alpha_{s, o}}{\alpha_{s, o^{\prime}}}=\left(\frac{l_{s, o, t}}{l_{s, o^{\prime}, t}}\right)^{1-\sigma_{s}} \frac{w_{o}}{w_{o}^{\prime}}$ and summing up delivers:

$$
\frac{1}{\alpha_{s, o^{\prime}}}=\sum_{o=1}^{O}\left(\frac{l_{s, o, t}}{l_{s, o^{\prime}, t}}\right)^{1-\sigma_{s}} \frac{w_{o}}{w_{o}^{\prime}}
$$

From the BLS Occupational Employment Statistics (OES) for the 2014-2019, data on wages for each of our occupational clusters are extracted and, once weighted by employment in each occupations, they are used to calibrate the steady state real wages in occupational clusters 1-8. See their value in Table 2. The same employment shares and wages are then used in equation 39 to calibrate the $\alpha_{s, o}$. 
Table 2: Sector and occupation share. Steady State Wage Distribution is calibrated on OES-BLS. Sector shares are calibrated on KLEMS data. Occupation weights $\alpha$ are obtained through steady state solution of model's equation and by using data for wages in each occupation.

\begin{tabular}{lcc}
\hline \multicolumn{1}{c}{ Name } & Symbol & Data \\
\hline Sector shares & $f_{s}$ & $0.19,0.18,0.03,0.15,0.24,0.03,0.16,0.02$ \\
Occupation shares & $\alpha_{s, o}$ & $0.078,0.254,0.092,0.280,0.035,0.085,0.070,0.106$ \\
Wage distribution & $w_{o}$ & $14.1,40.8,16.7,46.3,6.2,14.9,12.8,18.9$ \\
\hline
\end{tabular}

\subsection{Other Parameters}

Time is in quarters. Most of the other parameters are set according to values generally used in models with heterogeneous agents and uninsurable risk. In the most cases values are set to reach certain targets for asset distributions. The steady state interest rate on government bonds is calibrated to 0.0125 , close to the 5-year average of the Effective Federal Funds Rate (see Auclert et al. (2019)). The time discount factor, $\beta$, is then obtained from the asset market clearing condition. The portfolio adjustment cost parameter $\chi_{1}$ is set to 6.19 to match the quarterly interest rate of 0.0125 and the debt to output ratio of 1.04 . Following Auclert et al. (2019) the portfolio adjustment costs parameters are set as follows $\chi_{0}=0.25$ and $\chi_{2}=2$ and the steady state mark-up is set to 1.015 in order to match the steady state sum of liquid and non-liquid assets, which in our model is 16.26. The steady state level of government spending is set to 0.2 of GDP (a widely used "great ratio" from the literature). The value of taxes is then obtained from the fiscal policy rule and is equal to 0.4. In the baseline we fix the interest rate. Impulse responses are also shown under the Taylor rule with 1.5 for the weight on the inflation gap and 0 for the weight on the output gap. The slope of the Phillips curve, the capital depreciation rate and the capital adjustment costs are calibrated to 0.1, 0.02, and 4, respectively, following both Kaplan et al. (2018) and Auclert et al. (2019).

The flow value of non-employment, $h_{t}$, is calibrated using data from Chodorow-Reich and Karabarbounis (2016) who estimate the opportunity cost of employment using a wide range of data sources (Consumer Expenditure Survey (CES), the Panel Study of Income Dynamics (PSID) and the Current Population Survey (CPS)). Under separable preferences, which is the case considered in our model, they report a ratio of opportunity cost of employment to 
Table 3: Parameter Values, Description and Source

\begin{tabular}{|c|c|c|c|}
\hline Parameter & & Description & Value and source \\
\hline \multicolumn{4}{|c|}{ Skills and Occupations } \\
\hline & $O$ & Number of occupations & 8 , clustered by k-means \\
\hline & $J$ & Number of skill types & 8 , clustered from $\mathrm{O}^{*} \mathrm{NET}$ \\
\hline & $m_{j}$ & Distribution of skill types & $1 / J$ (uniform across $J)$ \\
\hline & $\Gamma$ & Skill transferability matrix & See Section 5.1 \\
\hline \multicolumn{4}{|c|}{ Final Composite Good } \\
\hline & $S$ & Number of sectors & $1(2$ in 7.4$)$ \\
\hline & $P_{t}$ & Aggregate Price & $\begin{array}{l}\text { Normalized to } 1 \text { in the } \\
\text { steady state. }\end{array}$ \\
\hline \multicolumn{4}{|c|}{ Production Function } \\
\hline & $\sigma_{s}$ & Elasticity of substitution between occupations & 0.2 (baseline) \\
\hline & $\nu_{s}$ & Capital share & 0.4, KLEMS, Section 5.2 \\
\hline & $w^{o}$ & $\begin{array}{l}\text { steady state wage per efficiency unit in occu- } \\
\text { pation } o\end{array}$ & OES-BLS, see Section 5.2 \\
\hline & $\delta$ & Capital depreciation & 0.02, Auclert et al. (2019) \\
\hline & I & Capital adj. parameter & 4, Auclert et al. (2019) \\
\hline \multicolumn{4}{|l|}{ Households } \\
\hline & $\beta$ & Time discount factor & 0.979, see Section 5.3 \\
\hline & $\chi_{0}$ & Portfolio adj. cost pivot & 0.25 , Auclert et al. (2019) \\
\hline & $\chi_{1}$ & Portfolio adj. cost scale & $\begin{array}{l}6.19\left(\operatorname{target} \mathcal{B}_{h}=1.04 Y, \mathrm{Au}-\right. \\
\text { clert et al. }(2019))\end{array}$ \\
\hline & $\chi_{2}$ & Portfolio adj. cost curvature & 2, Auclert et al. (2019) \\
\hline & $\sigma$ & EIS & 0.5 Auclert et al. (2019) \\
\hline & $\rho$ & Inverse Frisch elasticity & 1 Auclert et al. (2019) \\
\hline & $\rho_{z}$ & Autocorrelation of earnings & 0.966, Auclert et al. (2019) \\
\hline & $\sigma_{z}$ & Cross-sectional std of log earnings & 0.92, Auclert et al. (2019) \\
\hline & $h_{t}$ & Flow value of non-employment & $\begin{array}{l}47 \% \text { of average income, see } \\
\text { Section } 5.3 \text { Auclert et al. } \\
\text { (2019) }\end{array}$ \\
\hline & $\varphi$ & Dis-utility parameter & $1.71($ target $n=1)$ \\
\hline \multicolumn{4}{|c|}{ Asset Markets } \\
\hline & $r$ & Real interest rate & 0.0125, Auclert et al. (2019) \\
\hline & $\psi$ & Liquidity premium & 0.005, Auclert et al. (2019) \\
\hline & $\mu_{p}$ & steady state markup & 1.015, Auclert et al. (2019) \\
\hline \multicolumn{4}{|c|}{ Monetary and Fiscal Policy } \\
\hline & $\phi$ & Coefficient on inflation in Taylor rule & 1.5, Auclert et al. (2019) \\
\hline & $\phi_{y}$ & Coefficient on output gap in Taylor rule & 0, Auclert et al. (2019) \\
\hline & $\tau$ & Tax rate & 0.401, Auclert et al. (2019) \\
\hline & $\mathcal{B}_{g}$ & Bond supply & 2.8, Auclert et al. (2019) \\
\hline & $\kappa$ & Slope of the Phillips curve & 0.1, Auclert et al. (2019) \\
\hline \multicolumn{4}{|l|}{ SIR Block } \\
\hline & $\beta_{S I R}$ & Contact rate & $\begin{array}{l}\text { 1.5 Eichenbaum, Rebelo and } \\
\text { Trabandt (2020b) }\end{array}$ \\
\hline & $\gamma_{S I R}$ & Inverse of the infectious period & 0.8 \\
\hline & $\vartheta^{\circ}$ & Occupation infection risk & See Section 5.3 \\
\hline
\end{tabular}


the marginal product of employment (47\%). This value is then multiplied by our average steady state income for all employed households and delivers a value of 0.16. For comparison, households' steady state income (see eq. (1)) varies in our model between 0.06 and 1.15. This opportunity cost includes unemployment insurance and other benefits like Medicaid as well as foregone value of non-working time expressed in units of consumption.

Finally the SIR block is calibrated as in Eichenbaum et al. (2020b). Their basic reproduction number, which is set to 1.5 , is used to calibrate $\beta_{S I R}$ and $\gamma_{S I R}$, which is then set to 0.8 . At last, $\vartheta^{\circ}$ is parameterized according to the average infectiousness of the occupations in our broad occupational clusters. Infectious risk is measured using O*NET data and is as follows: $0.037,0.031,0.034,0.029,0.043,0.036,0.039,0.033$. Table 3 contains the list of those parameters.

At last, shocks in the numerical application are calibrated as follows. The infection shock is initiated through an increase in $\varepsilon_{\text {pandemic }}$ of $10^{-4}$. The occupational shock is done by shrinking the occupational weight in occupation 7 (retail, sales, etc.) by $60 \%$ and by raising the occupational weight in occupation 5 (health) by 10\%. The persistence of the shocks is set to 0.7 .

\subsection{Solution Method}

We solve the model using the Sequence Spaced Jacobian Solution Method built by Auclert et al. (2019). The method accounts for the impact of shocks on expectations. This is important in our model because it features (1) an endogenous policy response and (2) a SIR block, which brings the economy from one steady state to another. We extend the solution method to include endogenous occupational choice. To this purpose we add a guess-and-verify procedure for solving the households' two-stage optimization problem. Specifically, using a guessed value function, we obtain the policy functions for the consumption-saving problem for each occupation. The latter are then substituted into the value functions to solve for the optimal discrete occupational choice. The guess is updated until convergence. Appendix B contains a detailed description of our algorithm. Note that the equilibrium is not locally indeterminate 
based on the winding number check introduced by Auclert et al. (2019), which is analogous to the Blanchard-Kahn condition.

\section{Quantitative Results}

In this section our model is simulated to assess its quantitative properties. We start with the steady state results, the goal being of assessing the empirical fit of the model to the long-run cross-sectional distributions, with a focus on occupational sorting, and its link to inequality, and the matching of the model-generated income and wealth distributions to the data. Second, we simulate the dynamic response of the model under a standard 25 basis point contractionary monetary policy shock and compare the results to the ones from a model without occupational mobility. Our goal is to describe the novel channels in our model.

\subsection{Steady State Results}

\subsubsection{Occupational Sorting}

Table 4 shows effective labor hours in the steady state supplied in each occupation by each household type. The rows correspond to different household types, and the columns correspond to different occupations. Each entry equals the effective labor hours supplied in each occupation aggregated across idiosyncratic income shocks and asset holdings, i.e. $\int \gamma_{j}^{o} e_{t} \theta_{j}\left(o \mid e_{t}, a_{t-1}, b_{t-1}\right) n_{j, t}^{o} d D_{j, t}\left(e_{t}, a_{t-1}, b_{t-1}\right)$. We find that, first, households supply most hours in the occupation in which they have the highest comparative advantage (i.e., in each row, the entry on the diagonal of the matrix is the highest). Second, across occupations, effective labor supply is higher in occupations with higher wages, namely occupation 2 (Management) and occupation 4 (Engineering).

The probability of choosing an occupation depends on skills and wealth. In our model, in steady state asset-rich individuals are effectively indifferent between non-employment or work in any of the eight occupations. In contrast, we find a much tighter link between labor income and occupational choice for the asset-poor individuals. Table 5 shows the steady state probabilities of choosing an occupation for households in the lower ten percent 
Table 4: Effective Labor Supply by Occupation and Household Type, in the Steady State. Each matrix entry shows the effective labor hours supplied in each occupation in the steady state aggregated across idiosyncratic income shocks and asset holdings, i.e. $\int \gamma_{j}^{o} e_{t} \theta_{j}\left(o \mid e_{t}, a_{t-1}, b_{t-1}\right) n_{j, t}^{o} d D_{j, t}\left(e_{t}, a_{t-1}, b_{t-1}\right)$. Each row represents a household's skill type. Each column represents an occupation. The diagonal entries represent households' types with highest level of occupational skills. See text for the definition of households' types and how they relate to the occupations. The last row presents the sum across household types.

\begin{tabular}{lllllllllll}
\hline Household Type & Occ. $\mathbf{1}$ & Occ. $\mathbf{2}$ & Occ. $\mathbf{3}$ & Occ. 4 & Occ. 5 & Occ. $\mathbf{6}$ & Occ. $\mathbf{7}$ & Occ. 8 \\
\hline Type 1 & 0.151 & 0.123 & 0.114 & 0.125 & 0.113 & 0.123 & 0.111 & 0.113 \\
Type 2 & 0.109 & 0.163 & 0.110 & 0.122 & 0.121 & 0.111 & 0.109 & 0.112 \\
Type 3 & 0.116 & 0.123 & 0.152 & 0.123 & 0.112 & 0.120 & 0.115 & 0.114 \\
Type 4 & 0.109 & 0.133 & 0.110 & 0.164 & 0.116 & 0.111 & 0.109 & 0.111 \\
Type 5 & 0.109 & 0.135 & 0.110 & 0.124 & 0.146 & 0.113 & 0.109 & 0.111 \\
Type 6 & 0.110 & 0.133 & 0.111 & 0.130 & 0.121 & 0.151 & 0.110 & 0.113 \\
Type 7 & 0.111 & 0.128 & 0.113 & 0.124 & 0.114 & 0.119 & 0.150 & 0.117 \\
Type 8 & 0.110 & 0.139 & 0.111 & 0.127 & 0.115 & 0.116 & 0.110 & 0.153 \\
\hline Sum across types & 0.926 & 1.076 & 0.931 & 1.039 & 0.959 & 0.963 & 0.922 & 0.945 \\
\hline \hline
\end{tabular}

of the wealth distribution for three different realizations of the idiosyncratic income shock. First, regardless of the realization of the income shock, the households choose occupations with the highest wages (occupations 2 and 4). For example, Böhm, Gaudecker and Schran (2019) document the empirical link between high wages and expanding occupations. Second, households with the low income realization are more likely to choose non-employment than the households with high or medium realization of income shock. Third, for the households with the high income realization skills play a more important role in their occupational choice as compared to the households with lower income realization, who choose occupations with the highest wage. This is consistent with Gathmann and Schönberg (2010) who find that occupational switching is more likely to occupations with higher wage growth or higher skill price. Finally, the patterns featured in our model are consistent with the statistics on employment patterns across the wealth distribution as reported in Mustre-del Rio (2015) from the National Longitudinal Survey of the Youth (NLSY) data. First, heterogeneity in labour shares in Table 5 is not all driven by wages, but is also associated with skills and wealth. Second, the income-rich households in Table 5 have larger employment shares (lower non-employment shares) than the income-poor individuals. On the other hand, the assetrich individuals in our model, due to their better ability to smooth consumption, are more inclined to choose non-employment than the asset-poor individuals. 
Table 5: Occupational Choice of Asset-Poor Individuals, in the Steady State. The table shows the probabilities of choosing occupations and the non-employment state for the asset-poor households, aggregated across all skill types. The asset-poor are those at the bottom $10 \%$ of both the liquid assets distribution and the illiquid assets distribution.

\begin{tabular}{llllllllll}
\hline \multicolumn{1}{c}{ Income shock } & Occ. 1 & Occ. 2 & Occ. 3 & Occ. 4 & Occ. 5 & Occ. 6 & Occ. 7 & Occ. 8 & Non-employment \\
\hline Low & 0.095 & 0.167 & 0.100 & 0.172 & 0.086 & 0.097 & 0.093 & 0.105 & 0.086 \\
Medium & 0.107 & 0.138 & 0.117 & 0.140 & 0.084 & 0.113 & 0.102 & 0.121 & 0.078 \\
High & 0.114 & 0.127 & 0.116 & 0.129 & 0.096 & 0.115 & 0.114 & 0.117 & 0.072 \\
\hline
\end{tabular}

\subsubsection{Income and Wealth Distributions}

Table 6 shows the income and asset distribution statistics in the model and in the data. We compute the empirical statistics from the Survey of Consumer Finance (SCF). Liquid assets consist of the following categories: transactions accounts, directly held bonds, directly held stocks, and credit card balances. Non-liquid assets consist of certificate of deposits, savings bonds, cash value of insurance, other managed assets, retirement accounts, stock holdings, and primary residence net of mortgage home loans. To facilitate the comparison with the steady state numbers in the model, we average the SCF statistics across all available years, 1989-2019. We compute the average asset holdings by different wealth and income percentiles.

The model captures well the average holdings of liquid and illiquid assets (the first two rows in Table 6). The model's Gini coefficients compare well to the empirical Gini coefficients reported in the World Inequality Database and Kaplan et al. (2018). Next, the model matches fairly well the mean assets holdings by different percentiles of the income distribution. The main drawback lies in the top $10 \%$ for illiquid asset holdings, which is larger in the data. Overall the matching is encouraging given that the labor income distribution is endogenous in the model. The SCF data also contain information on income and assets by broad occupational groups. We compare the SCF group "Managers" to our occupations 2 and 4, and the SCF group "Technical, Sales, Services" to our occupations 5, 6 and 7. The ratios of mean income to liquid assets in the model compare well to the data.

Appendix F contains plots of wealth and wage distributions. The wealth distributions are skewed. The distribution of liquid assets exhibits a peak at zero, which corresponds to the 
Table 6: Income and Asset Distributions, Model's steady state and Data. The model statistics are calculated at the steady state. Income statistics from the model includes pre-tax labor income and capital gains but do not include inactivity benefits. Data on income, liquid and non-liquid assets are from the Survey of Consumer Finance, averages over 1989-2019. Liquid assets consist of transactions accounts, directly held bonds, directly held stocks, and credit card balances. Non-liquid assets consist of certificate of deposits, savings bonds, cash value of insurance, other managed assets, retirement accounts, stock holdings, and primary residence net of mortgage home loans. The deciles for illiquid assets holdings are based only on the value of primary residence. The data on Gini coefficients are from the World Inequality Database and Kaplan et al. (2018).

\begin{tabular}{llc}
\hline Statistics & Data & Model \\
\hline Wealth distribution & & \\
Mean Liquid Assets/GDP & 0.26 & 0.26 \\
$\quad$ Median Illiquid/GDP & 2.92 & 3.80 \\
Gini coefficients & 0.52 & 0.39 \\
$\quad$ Income & 0.98 & 0.71 \\
Liquid assets & 0.81 & 0.50 \\
Illiquid assets & & \\
Shares of liquid assets per income percentile & 0.05 & 0.04 \\
less than 20th percent. & 0.10 & 0.13 \\
20th-40th percent. & 0.08 & 0.12 \\
40th-60th percent. & 0.13 & 0.21 \\
60th-80th percent. & 0.63 & 0.39 \\
80th-100th percent. & & \\
Shares of illiquid assets per income percentile & 0.07 & 0.06 \\
less than 20th percent. & 0.09 & 0.07 \\
20th-40th percent. & 0.11 & 0.15 \\
40th-60th percent. & 0.15 & 0.29 \\
60th-80th percent. & 0.57 & 0.28 \\
80th-100th percent. & 1.80 & 1.48 \\
Income/Liquid Assets, by Occupation & 2.74 & 3.92 \\
Managers and Professionals & & \\
Technical, Sales and Services & & \\
\hline
\end{tabular}


share of the hand-to-mouth households in the model. In our simulations at the recession's trough, the upper tail becomes thinner and the lower tail fatter. This is even more so for the non-liquid assets distribution.

\subsection{Dynamic Responses to Standard Monetary Policy Shock}

In this section, we simulate the model's response to a standard 25 basis point contractionary monetary policy shock. We then compare our model to a model without mobility, where the occupational choice remains fixed at the steady-state values. Our goal is to characterize the channels that arise in the model with mobility as compared to a model without mobility. Figure 1 displays the impulse responses for selected variables, namely GDP, investment, consumption, policy rule, aggregate average wage (weighted by shares in each occupation), total effective labor hours, inflation, the wage Gini, effective labor hours across occupations (only in the model with occupational mobility), illiquid and liquid assets. As expected the shock is contractionary. The baseline channels noted elsewhere in the literature studying heterogeneous agents models with uninsurable risk and with nominal rigidities are operative

here as well. Aggregate consumption falls due to precautionary saving. The latter also induces a flight to liquidity, as households substitute non-liquid with liquid assets. Investment falls due to the paradox of thrift - as households save more, demand and output decline. The monetary transmission is characterized by the typical three channels - the earnings heterogeneity channel, the Fisher effect and the interest rate exposure channel (see Auclert (2019)). The first channel implies that households reduce consumption in response to the decline in income or changes in interest rates, the more so the higher their marginal propensity to consume. The second channel accounts for changes in demand induced by deflationary/inflationary expectations. The third channel produces changes in the asset distribution, which vary across households according to their interest rate exposure.

The model with occupational mobility is characterized by two additional channels. First, the decline in wages induces some workers to opt out of employment and this may worsen the contraction. This channel is playing an increasing role particularly in recent recessions, which were followed by jobless recoveries. While the size of the shock considered here is rather 

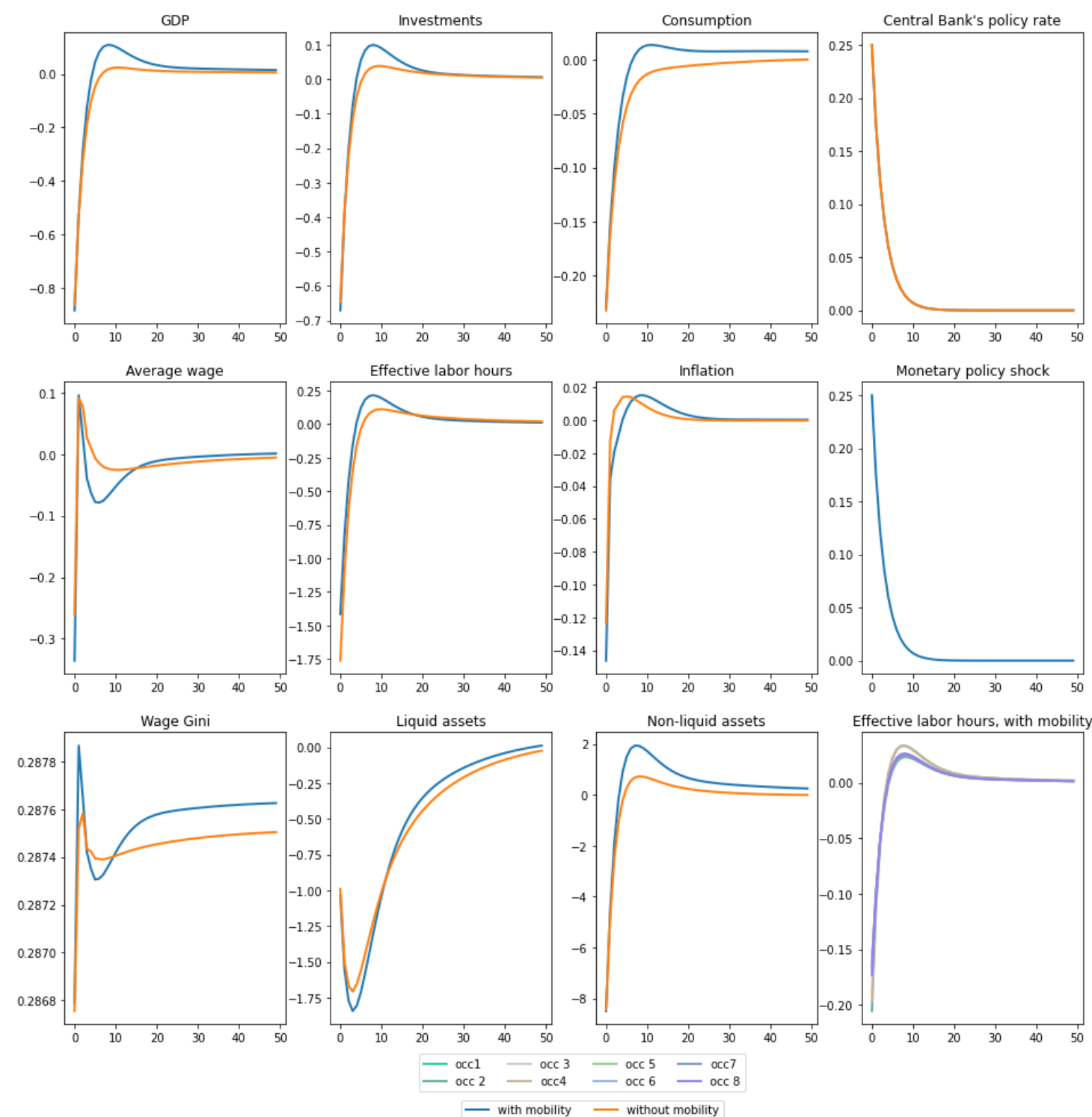

Figure 1: Impulse Responses to a Monetary Policy Shock. The figure shows the percentage deviations of the specified series from the steady state in response to a monetary policy shock. The shock is a 25 b.p. increase in the Central Bank's interest rate; the shock follows an AR(1) process with the persistence parameter 0.7 , such that the shock almost dissipates by the $13^{\text {th }}$ quarter. The figure shows the impulse responses from the model with the occupational mobility (in blue) and from the model without it (in orange). Central Bank follows the Taylor rule. The average wage is the weighted average wage across occupations where the weights are occupational employment shares in terms of efficiency units. The effective labor hours is the sum of the labor hours across occupations. Wage Gini is presented in absolute values. Occupational labor dynamics are shown in the last panel, where each line corresponds to the effective labor hours in the specified occupation. $\mathrm{X}$-axis shows the time in quarters. 
small, this channel may play a more substantial role in larger recessions. Second, workers can reallocate from shrinking to expanding occupations. The reallocation channel can tame a recession. In this particular shock the second channel seems to prevail. However, more generally whether the first or the second channel prevail may vary (as we will see below), depending on the type of shock and its magnitude, the policy stance and other structural characteristics of the economy. In particular, the reallocation channel is amplified under sectoral or occupational shocks like the ones we consider below in the pandemic application.

Note that even in the model with fixed probabilities some changes in labor hours take place due to changes in labor demand and in labor supply, through the impact on labor dis-utility. Still, in our model changes occur more realistically through the extensive margin and, despite the small size of the shock, those matter in driving the macro dynamic.

The reallocation channel has further implications for earnings inequality. The wage Gini (first panel, last row) fluctuates more in the model with mobility. Generally speaking, while the recession in the model with reallocation may be tamed, the income inequality tends to worsen.

The aggregate shock described above is not the ideal setting in exploiting the properties of our model: it is an aggregate small shock which evenly hits all sectors. Our occupational reallocation mechanism can be best exploited in a setting with a large recessionary shock, pushing many workers out of employment, and unevenly hitting the economy. For this reason the model is applied next to the recent pandemic recession, with the latter features a marked reallocation channel through a unique combination of uneven and persistent occupational or sectoral shocks and aggregate labor supply shocks.

\section{An Application of the Model to the Pandemic Recession}

Our model provides a laboratory for studying the role of occupational reallocation in the economy's response to shocks. We apply the model to the pandemic recession. The pandemic recession involves two types of shocks - a negative aggregate labour supply shock 
due to the infections and a demand shock triggered by government-mandated lockdown. The role of occupational mobility differs under these two shocks. Under the infection shock, all occupations are hit, and little occupational reallocation takes place. Under the government-mandated lockdown, occupations are hit differentially, which triggers occupational reallocation.

We, first, examine the effect of the occupational demand shocks and the aggregate supply shock separately, and then jointly. Studying model under each shock separately helps demonstrate the model's mechanism.

To investigate the role of skill mismatch and skill transferability, we simulate the model under different degrees of job specialization, which is captured by the elasticity of substitution across occupations in the production function, $\sigma$, and under different degrees of workers' skill transferability across occupations, which is captured by the skill-distribution matrix, $\Gamma$. This analysis helps understand how the economies with different distribution of skills and educational attainment or with different production structure respond to various shocks.

While sticky prices are not essential for studying occupational reallocation and the economy's response in the long-run, price rigidity affects the economy's short-run response to shocks and stabilization policy. To dissect the role of policies, we, additionally, examine the model's response under different monetary policies - the standard Taylor rule and the zero lower bound policy.

We begin our investigation by studying reallocation in an eight-occupation one-sector model. We then simulate an eight-occupation two-sector model, which allows examining the effect of sector-specific in addition to the occupational shocks. To demonstrate the role of occupational mobility, we compare the results from our model with occupational mobility to a HANK model without occupational mobility.

\subsection{Occupational Shocks}

The government-mandated lockdown during the pandemic of nonessential sectors resulted in a positive demand shock for some occupations and a negative demand shock for others. While the lockdown concerned sectors and not occupations, the resulting shock manifested 
itself through occupations. For example, the shutdown of dining-in restaurants resulted in a negative demand shock to waiters but a positive demand shock for delivery workers. Another important feature of the occupation-specific shocks during the pandemic is the differential persistence of these shocks across occupations. While the lockdowns were shortterm, the resulting occupational demand shocks might be persistent and the demand for some occupations might not return to their initial levels. Firms might automate, employ new technologies, and reorganize their production. For example, Autor and Reynolds (2020) argue that the pandemic has poised to reshape labor markets due to telepresence, urban de-densification, employment concentration in large firms, and general automation forcing, and that those trends will induce disappearance of certain occupations, mostly face-to-face ones. ${ }^{8}$ Our model allows us studying the economy's response to the various occupational shocks with differential persistence. ${ }^{9}$

We model the occupational shock as an exogenous and persistent change in occupationspecific shares in the production function, $\alpha_{s, o}$. Our baseline occupational shock is a combination of shocks to two occupations: a $10 \%$ increase in the production share of occupation 5 (healthcare) and a $60 \%$ decline in the production share of occupation 7 (which includes service-related and sales occupations). The large close down of one occupation is meant to mimic the stringency measures that applied to most nonessential services. In most countries about $60 \%$ of the economic activity had been restricted. We model each occupational shock as an $\operatorname{AR}(1)$ process with persistence 0.7 , so that the shock dissipates after 13 quarters. We simulate the shock in the economy with 8 occupations and one sector. For our baseline results, the monetary policy has a fixed interest rate (which we would refer as the zero lower bound case), as this was the scenario enacted in response to the pandemic recession.

Figure 2 shows the dynamics for selected aggregate variables, inequality measures and occupational mobility. Figure 2 shows GDP, investment, consumption, the policy rate,

8 Chernoff and Warman (2020) examine regional and country variation in jobs concentrated in high-risk and highly-automatable occupations and find that these occupations exhibit the highest likelihood of disappearing post-pandemic.

9 Moll, Rachel and Restrepo (2021) studies the effect of automation on wealth inequality in an Aiyagari-style model but without occupational choice. Our model allows studying the effect of automation on income and wealth inequality allowing workers to change their occupation when their jobs get automated. 
aggregate wage (average wage across occupations, weighted by the occupational labor shares), total effective labor hours, the share of population in the non-employment state, the wage Gini, dynamics of wages in different occupations, liquid assets and non-liquid assets, occupational choice probabilities and the share in the non-employment state. All series (except the occupational choice probabilities and the wage Gini coefficients) are in the percentage deviations from their steady state levels. The figure shows the impulse responses from the model with occupational mobility (blue lines) and without occupational mobility (orange lines).

First, the fall in the GDP is sizable. In most economies the fall in GDP was larger, but it was due to a combination of recessionary shocks or to stricter stringency measures than the ones simulated here. Beyond that, the fall in GDP, observed in various countries, was also likely driven by which sectors were hit by stringency measures and how large are those sectors. For instance Figure 10 in Appendix E shows the impact of a $60 \%$ closure of occupations in the second cluster, this includes sales, education, other business, but also managerial positions in finance, hence also other likely sectors which were hit by the lock down measures. As this sector accounts for a large share of the economy, a similarly sized shock as in the baseline, but in occupation 2, has a much bigger impact on GDP. The decline in this case is around $18 \%$. To sum up, the exact decline of output is likely to depend on many factors which may vary across economies and that can be accommodated within our model.

Second, as before the standard channels of models with uninsurable risk are also at work here. Precautionary savings reduces consumption and induces a flight to liquidity, the paradox of thrift induces the investment decline. Beyond that, the occupational shock induces a reallocation from shrinking to expanding occupation, which should tame the recession. On the other side, the increase in income dispersion may deepen the fall in demand, by sharpening precautionary saving motives, and the large fall in wages induces some workers to opt of the labor force. ${ }^{10}$ The last two forces prevail, and the recession is deeper as compared to the model without mobility.

Two observations are worth noting here in relation to the reallocation mechanism.

10 The model without mobility also features a change in labor hours via intensive labor hours choice. 
First, the dynamics of the earnings inequality depend on the occupations that are hit. We analyze the negative shock to occupation 7 (retail, sales, etc.) which has a low wage. On the other hand, if high-wage occupations face negative shocks, we see a decrease in the wage Gini (for example, if the shock occurs in the occupation 2 (Management)). Figure 11 in Appendix E for instance show that while inequality raises (wage Gini raises) when the shock hits a high wage occupation (occupation 2 employing mainly managerial services in various sectors), the opposite is true when the shock hit a low-wage occupation (occupation 1 for instance, namely construction). While the nature of this exercise is purely suggestive, its implications may be relevant for other applications of our model. For instance, the raise in inequality associated with the 2007-2008 financial crisis is likely induced, through the lens of our model, by the prevalence of the shocks in low-wage occupations.

Second, reallocation induces a cost proportional to the distance in skill-requirements between past and new occupations. To fix ideas consider workers, whose talents are closer to the skill-requirements of occupation 7 . The closing of the latter forces them to reallocate to a new occupation, whose skill-requirement is most likely be further away from their own abilities, or to non-employment. In both cases they will face a wage cut.

Interestingly, simulations of the same shock under a Taylor rule (see Appendix E) show that, under this alternative policy stance, the reallocation across occupations is greater. As this channel prevails over the opt-out of employment channel, in this case the model with mobility tames the recession compared to the one without. In the absence of the sheltering provided by the expansionary policy workers reallocate more actively. This provides an interesting exchange between a policy, the ZLB, that fosters demand by enhancing income capacity, and a policy, the Taylor rule, that lubricates the labor market by activating mobility.

\subsection{The Role of Monetary Policy}

In our previous simulations, the monetary policy was held at the zero lower bound. This was the policy enacted soon after the start of the pandemic.

To discuss the role of policy, Figure 3 compares the impulse responses of selected variables for the model with occupational mobility under different monetary policy stances and in 

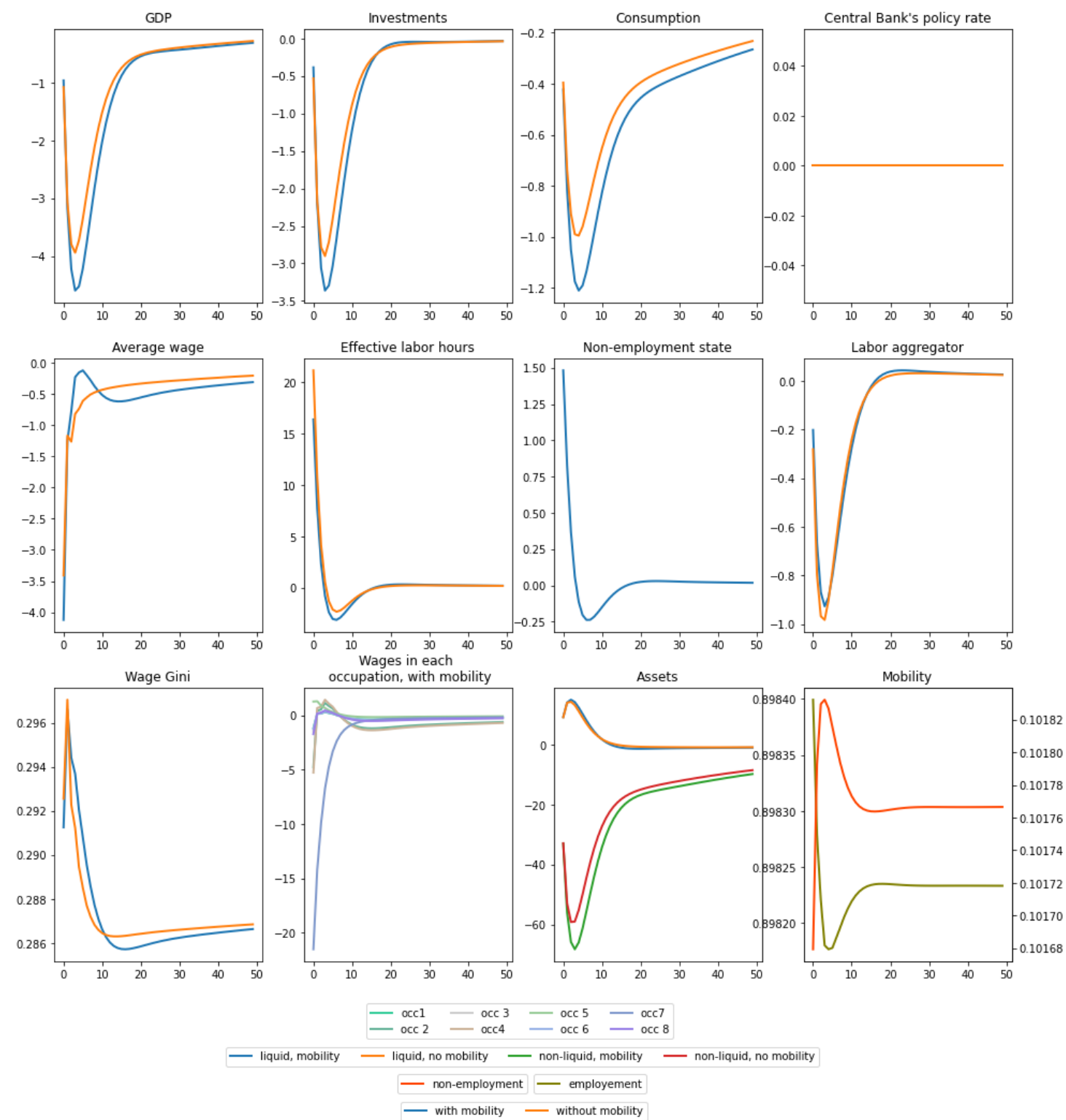

Figure 2: Impulse Responses to the Occupational Shock. The figure shows the percentage deviations of the selected variables from the steady state in response to an occupational shock. The occupational shock is a $10 \%$ increase in $\alpha_{5}$ and a $60 \%$ decrease in $\alpha_{7}$; each shock follows an $\operatorname{AR}(1)$ process with the persistence parameter 0.7 , such that the shock almost dissipates by the $13^{\text {th }}$ quarter. The figure shows the impulse responses from the model with the occupational mobility (in blue) and from the model without it (in orange). The average wage is the weighted average wage across occupations where the weights are occupational employment shares in terms of efficiency units. The effective labor hours is the sum of the labor hours across occupations. The non-employment share shows the share of households that choose non-employment. Labor aggregator is $L_{s}$ and shows the aggregated labor used in the production. Wage Gini is presented in absolute values. Occupational wage dynamics are shown in the last row, where each line corresponds to the wage in the specified occupation. Mobility panel shows probability (aggregated across households and occupations) of being employed and probability of being in the non-employed state (aggregated across households). Probability of being in the non-employed state is shown on the right axis. X-axis shows the time in quarters. 
response to the occupational shock. In each panel, the blue line represents the model under the ZLB and the yellow line the model under a Taylor rule.

First, since as explained earlier the ZLB curbs the reallocation across occupations, more workers opt out of employment (third panel, second row). Still, the zero rates have several effects. They tame the decline in consumption demand, by raising the marginal propensity to consume. As well understood by now, in heterogeneous agents models monetary policy has a differential impact on agents depending on their income distribution and on their asset allocation. Hence, the observed macroeconomic impact results from the aggregation of the differential effects.

Investment declines less under the ZLB. Investment declines when interest rate increases and when the marginal productivity of labor declines. While the second effect is present under both monetary policies, the first is absent under the ZLB. The lower decline in investment reduces the decline in production, which in turn reduces the decline in labor income in all occupations (first panel, second row). This raises the overall number of labor hours supplied under the ZLB compared to the Taylor rule. The increased earnings capacity raises consumption demand under the ZLB relatively to the Taylor rule. Although workers are less active in reallocating, the ZLB tames the recession due to the boost in demand. Interestingly, the ZLB stance also raises earnings' inequality (wage Gini in the first panel, the last row): since workers reallocate less across jobs, the differences in labor demand triggered by the occupational shocks are compensated by larger cross-sectional variation in wages.

\subsection{The Role of Job Specialization and Skill-Transferability}

As shown in propositions 2 and 3, the job substitutability, $\frac{1}{\sigma_{s}}$, affects the extent of reallocation, both in and out of employment and across occupations. To this purpose figure 4 shows the dynamics of the selected variables in response to the occupational shock comparing the model under $\sigma_{s}=0.2$ versus the model with $\sigma_{s}=0.5$. On the one side, and compatibly with our analytical derivations from Proposition 2, higher $\sigma_{s}$ implies for firms higher substitutability of labor or lower elasticity of labor demand to wages. This dampens reallocation across jobs. On the other side, the capital labor substitution declines as shown in Proposition 3. This 

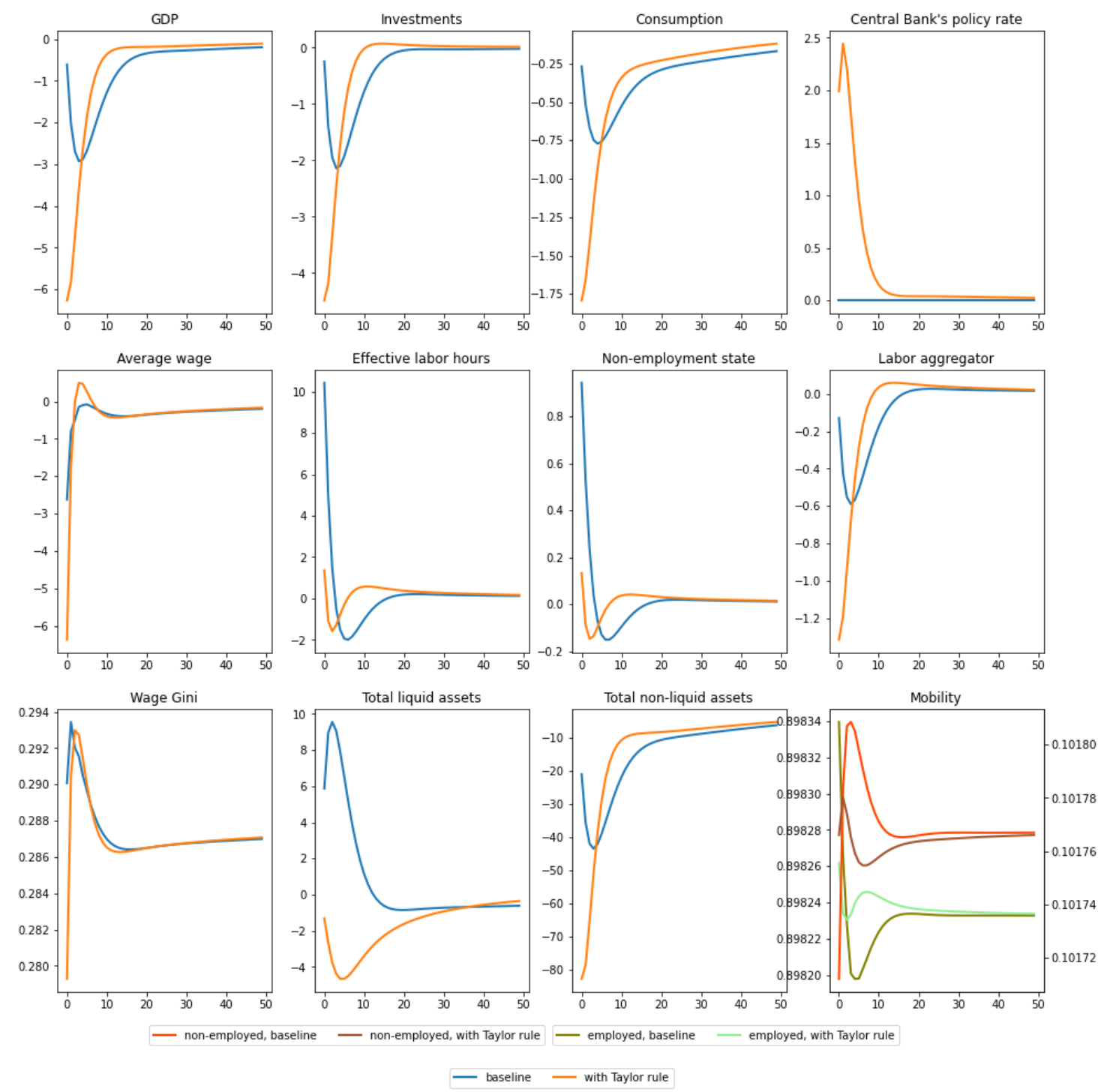

Figure 3: Impulse Responses to the Occupational Shock under the Zero Lower Bound (Baseline) and the Taylor Rule. The figure shows the percentage deviations of the selected variables from the steady state in response to an occupational shock. The occupational shock is a $10 \%$ increase in $\alpha_{5}$ and a $40 \%$ decrease in $\alpha_{7}$; each shock follows an $\operatorname{AR}(1)$ process with the persistence parameter 0.7, such that the shock almost dissipates by the $13^{\text {th }}$ quarter. The figure shows the impulse responses from the model with the ZLB (in blue) and from the model where the monetary policy is following the Taylor rule (in orange). The average wage is the weighted average wage across occupations where the weights are occupational employment shares in terms of efficiency units. The effective labor hours is the sum of the labor hours across occupations. The non-employment share shows the share of households that choose non-employment. Labor aggregator is $L_{s}$ and shows the aggregated labor used in the production. Wage Gini is presented in absolute values. Mobility panel shows probability (aggregated across households and occupations) of being employed and probability of being in the non-employed state (aggregated across households). Probability of being in the non-employed state is shown on the right axis. $\mathrm{X}$-axis shows the time in quarters. 
tames the fall in wages, reduces the fraction of workers that leave the labor force and reduces the decline in demand. The second effects prevails so that, for this shock, the recession is tamed under higher $\sigma_{s}$.

Another model's primitive that affects the extent of occupational reallocation in the model is the degree of workers' skill transferability across occupations. This is captured by the skewness of the skill distribution matrix, $\Gamma$.

Figure 5 compares impulse responses of selected variables to the occupational shock under the model with the baseline skill distribution matrix and with one characterized by the lower variance.

A more even skill distribution induces more reallocation in response to uneven shocks, as tasks are more substitutable for workers. On the other hand, income dispersion (the effect discussed above) increases even more (see wage Gini). While it is easier for firms to substitute workers, the wages go down more and hence consumption also declines more. Overall, with more even skill distribution, the effects that deepen recession are amplified, though quantitative magnitudes are relatively small.

\subsection{Sectoral Productivity Shocks in a Two-Sector Model}

Our model features reallocation both across occupations and across sectors. So far the focus has been on occupational reallocation. In this subsection, we consider a two-sector variant of the model and study the impulse responses to a sectoral productivity shock. In proposition 1 we have shown that the sectoral allocation of labor shares depends, among other things, on the weights $f_{s}$. The sectoral shock is therefore modelled as a negative shock to $f_{s}$ in one sector. Compatibly with the pandemic application, the latter is chosen to be "Accommodation and Food Service Activities, Arts, Entert., Rec. and Other Services". Most of labor in this sector is employed in occupations 6 and 7 (about 30\% in each). Therefore, the shock translates into a negative labor demand shock to occupations 6 and 7. Figure 6 shows dynamics of the usual macro, mobility and inequality variables. The effective labor hours and wages in the occupations involved by the closure go down. Overall the shock is recessionary triggering declines in consumption, investment and GDP. However, its negative impact is much smaller 

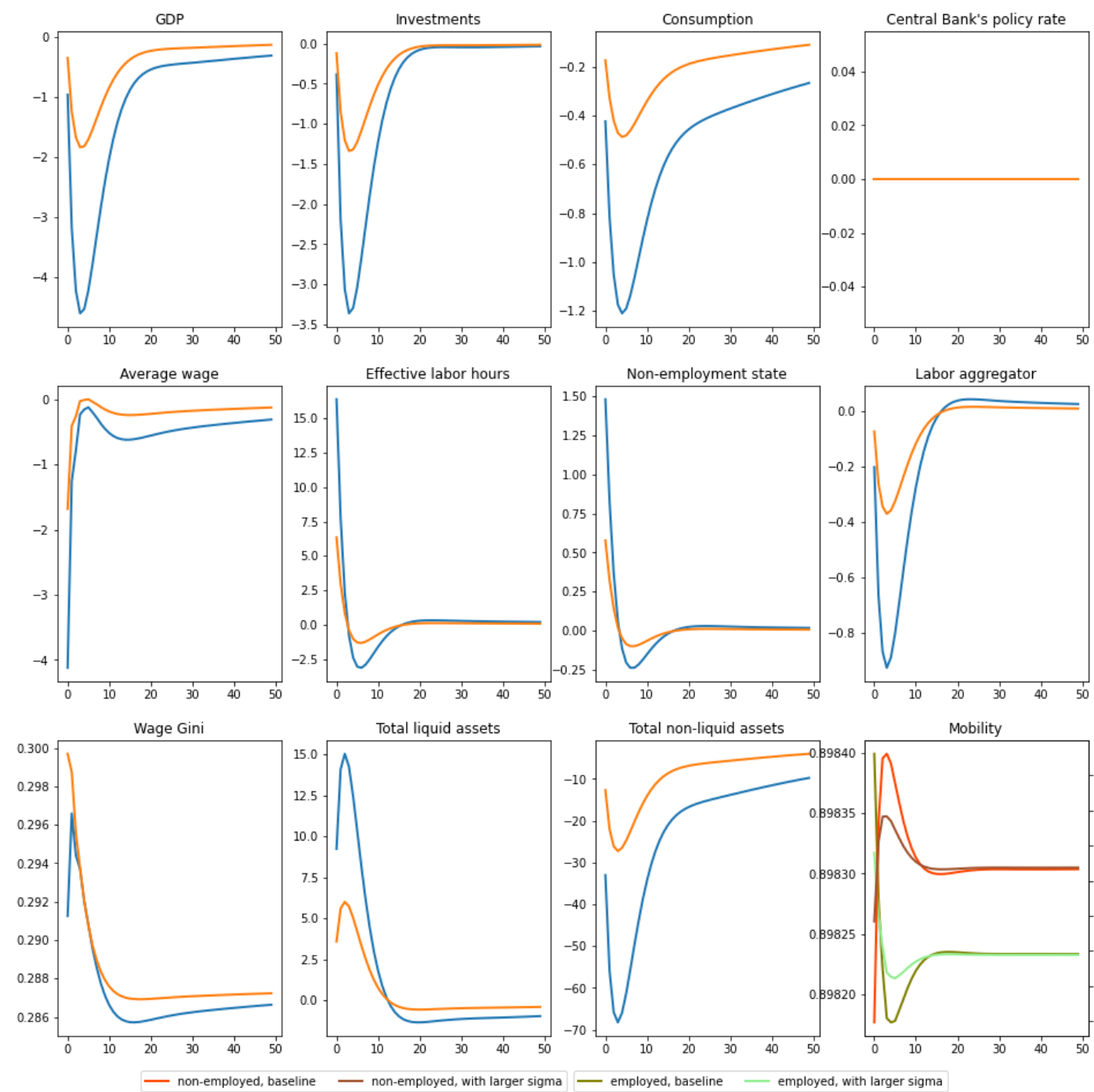

Mobility

$$
\text { — baseline — with higher substitutability }
$$

Figure 4: Impulse Responses to the Occupational Shock under Different Substitutability of Labor. The figure shows the percentage deviations of the selected variables from the steady state in response to an occupational shock. The occupational shock is a $10 \%$ increase in $\alpha_{5}$ and a $60 \%$ decrease in $\alpha_{7}$; each shock follows an $\operatorname{AR}(1)$ process with the persistence parameter 0.7, such that the shock almost dissipates by the $13^{\text {th }}$ quarter. The figure shows the impulse responses from the model with the baseline substitutability of labor (with $\sigma_{s}=0.2$ in blue) and from the model with a higher substitutability of labor (with $\sigma_{s}=0.5$ in orange). The average wage is the weighted average wage across occupations where the weights are occupational employment shares in terms of efficiency units. The effective labor hours is the sum of the labor hours across occupations. The non-employment share shows the share of households that choose non-employment. Labor aggregator is $L_{s}$ and shows the aggregated labor used in the production. Wage Gini is presented in absolute values. Mobility panel shows probability (aggregated across households and occupations) of being employed and probability of being in the non-employed state (aggregated across households). Probability of being in the non-employed state is shown on the right axis. X-axis shows the time in quarters. 

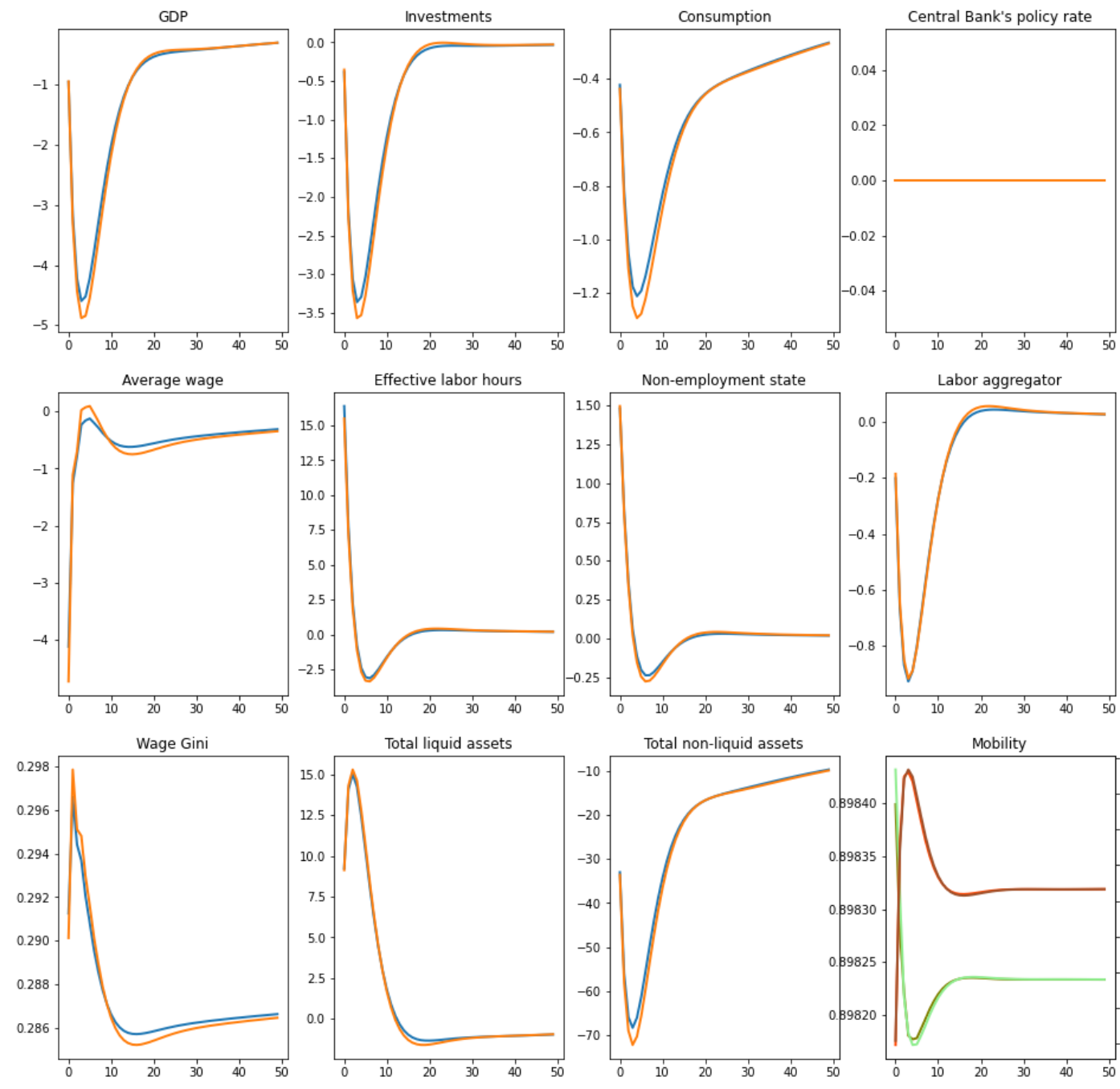

Mobility

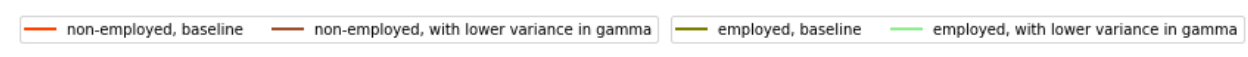

— baseline - with lower variance in gamma

Figure 5: Impulse Responses to the Occupational Shock under the Baseline and a Lower Variance of the Skill Distribution. The figure shows the percentage deviations of the selected variables from the steady state in response to an occupational shock. The occupational shock is a $10 \%$ increase in $\alpha_{5}$ and a $60 \%$ decrease in $\alpha_{7}$; each shock follows an $\operatorname{AR}(1)$ process with the persistence parameter 0.7 , such that the shock almost dissipates by the $13^{\text {th }}$ quarter. The figure shows the impulse responses from the model with the baseline degree of skill transferability across occupations (in blue), and from the model with a higher degree of skill transferability (in orange). $\gamma$ in the baseline model is obtained by using $\exp (\gamma) /(1+\gamma)$ transformation, $\gamma$ in the version with the lower variation in gamma is obtained as $\exp (\gamma) /\left(1+\gamma+\frac{\gamma^{2}}{2}\right)$. The latter $\gamma$ specification delivers four times smaller standard deviation (the skewness and kurtosis in the two specification are close to each other, with a bit larger values for the second specification, 1.7 vs. 2 for skewness and 4.5 vs. 5.3 for kurtosis). ). The average wage is the weighted average wage across occupations where the weights are occupational employment shares in terms of efficiency units. The effective labor hours is the sum of the labor hours across occupations. The non-employment share shows the share of households that choose non-employment. Labor aggregator is $L_{s}$ and shows the aggregated labor used in the production. Wage Gini is presented in absolute values. Mobility panel shows probability (aggregated across households and occupations) of being employed and probability of being in the non-employed state (aggregated across households). Probability of being in the non-employed state is shown on the right axis. X-axis shows the time in quarters. 
than that of the occupational shock. The reason is that only a fraction of the occupations in the closed sectors is hit by the shock.

\subsection{Aggregate Labor Supply Shock in an One-Sector Model}

This section examines the effects of the aggregate infection shock on labor supply. For the ease of the exposition, we simulate the shock in the one sector model.

We initiate the shock through an increase in $\varepsilon_{\text {pandemic }}$ of $10^{-4}$. Since the SIR model is non-linear and brings the economy to a new steady state, we use the non-linearized solution from Auclert et al. (2019). We extend the solution to include the possibility of the two steady states. $^{11}$

The shock reduces labor supply on impact, more so in occupations with high infection risk, $\vartheta^{\circ}$ (see equation 13). In our baseline calibration, the infection shock is long-lived so that the peak of the infection is reached after five years. The SIR reproduction number of 1.5 determines the length of the shock. The model abstracts from vaccinations and other measures which may alter its duration. ${ }^{12}$ This is so since agents internalize the effect of the shock and reduce the labor hours in risky occupations. Still, faster spread of the disease would magnify the impact of the labor supply shock.

Figure 7 shows the dynamics for selected macro, mobility inequality variables in response to an infection shock. Figure 7 shows macro variables: GDP, investment, consumption, the policy rate, aggregate wage (average wage across occupations, weighted by the occupational labor shares), total effective labor hours, the share of population in the non-employment state, and the labor aggregator, the wage Gini, non-liquid assets, liquid assets and infections. All series are in the percentage deviations from their steady state levels (except infection share and wage Gini).

The extent of reallocation across occupations under this aggregate shock is modest. Some reallocation occurs between high infection risk and low infection risk occupations. The bulk

11 Numerically our algorithm converges for shocks that are limited in size. This constrains the extent to which we can draw quantitative implications from the infection shock.

12 We do not attempt to make exact predictions on the unfolding of the infection, which depends on a combination of local geography, density, behavioural factors and social preferences. 

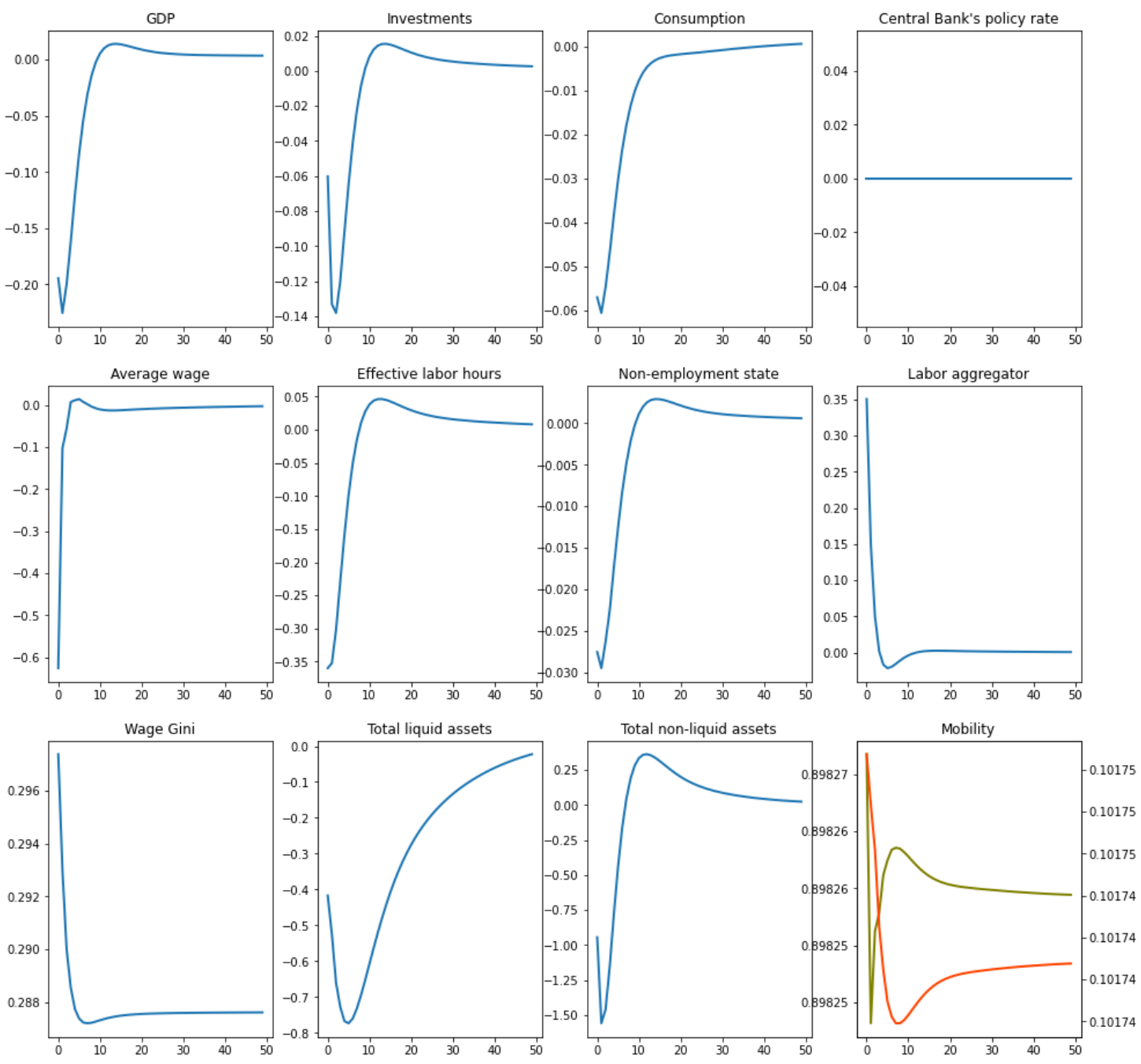

Figure 6: Impulse Responses to a Sectoral Shock in a Two-Sector Model. The figure shows the percentage deviations of the specified series from the steady state in response to a sectoral shock. The sectoral shock is a $90 \%$ decline in $f_{2}$ ( $f_{2}$ is $2.7 \%$ of the total economy); the shock follows an $\operatorname{AR}(1)$ process with the persistence parameter 0.7 , such that the shock almost dissipates by the $13^{\text {th }}$ quarter. The figure shows the impulse responses from the model with the occupational mobility (in blue). The average wage is the weighted average wage across occupations where the weights are occupational employment shares in terms of efficiency units. The effective labor hours is the sum of the labor hours across occupations. The non-employment share shows the share of households that choose non-employment. Labor aggregator is $L_{s}$ and shows the aggregated labor used in the production. Wage Gini is presented in absolute values. Mobility panel shows probability (aggregated across households and occupations) of being employed and probability of being in the non-employed state (aggregated across households). Probability of being in the non-employed state is shown on the right axis. $\mathrm{X}$-axis shows the time in quarters. 

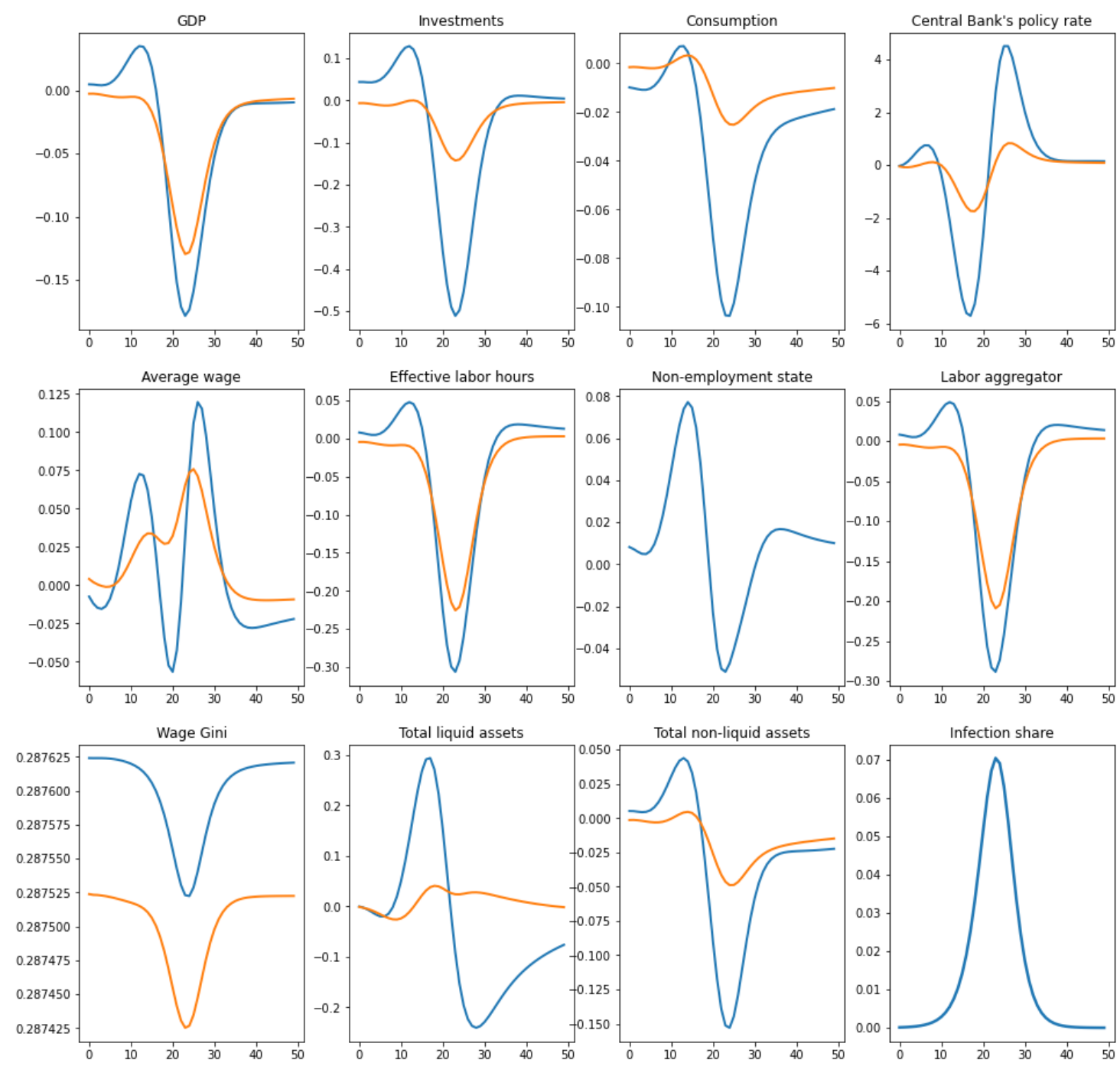

Figure 7: Impulse Responses to the Aggregate Labor Supply Shock. The figure shows the percentage deviations of the specified series from the steady state in response to the infection shock. The shock is an increase in $\varepsilon_{\text {pandemic }}$ by $10^{-4}$. The figure shows the impulse responses from the model with the occupational mobility (in blue) and from the model without it (in orange). The average wage is the weighted average wage across occupations where the weights are occupational employment shares in terms of efficiency units. The effective labor hours is the sum of the labor hours across occupations. The non-employment share shows the share of households that choose non-employment. Labor aggregator is $L_{s}$ and shows the aggregated labor used in the production. Wage Gini is presented in absolute values. The infected share is the share of the currently infected people in the population. X-axis shows the time in quarters. 
of the transmission is channelled through the share of workers in the non-employment state due to the fall in wages and the increase in the infection risk.

The wage Gini declines. Wages in high risky occupations, which were also low-wage occupations from the start, raise. This reduces income dispersion. Scheidel (2020) argues for a similar mechanism characterizing pandemics through history.

\subsection{Dynamic Response to Combined Aggregate Supply and Occupational Shocks}

Examining each shock separately helps to transparently discuss the model-channels. The occupational shocks highlight the extent of reallocation across occupations, the labor supply shock fine tunes the extent of reallocation in and out of employment.

The pandemic featured a rare combination of aggregate supply and occupational shocks. For this reason and to appreciate the combined effect of the two shocks, figure 8 plots the dynamic responses to both.

Overall, the recession depicts a more realistic $\mathrm{V}$-shape (see panels 1, 2 and 3 in the first row). Occupational reallocation in here is triggered both by the occupational shocks and by the varying infection risk across occupations. Both of them also reduce labor participation. 

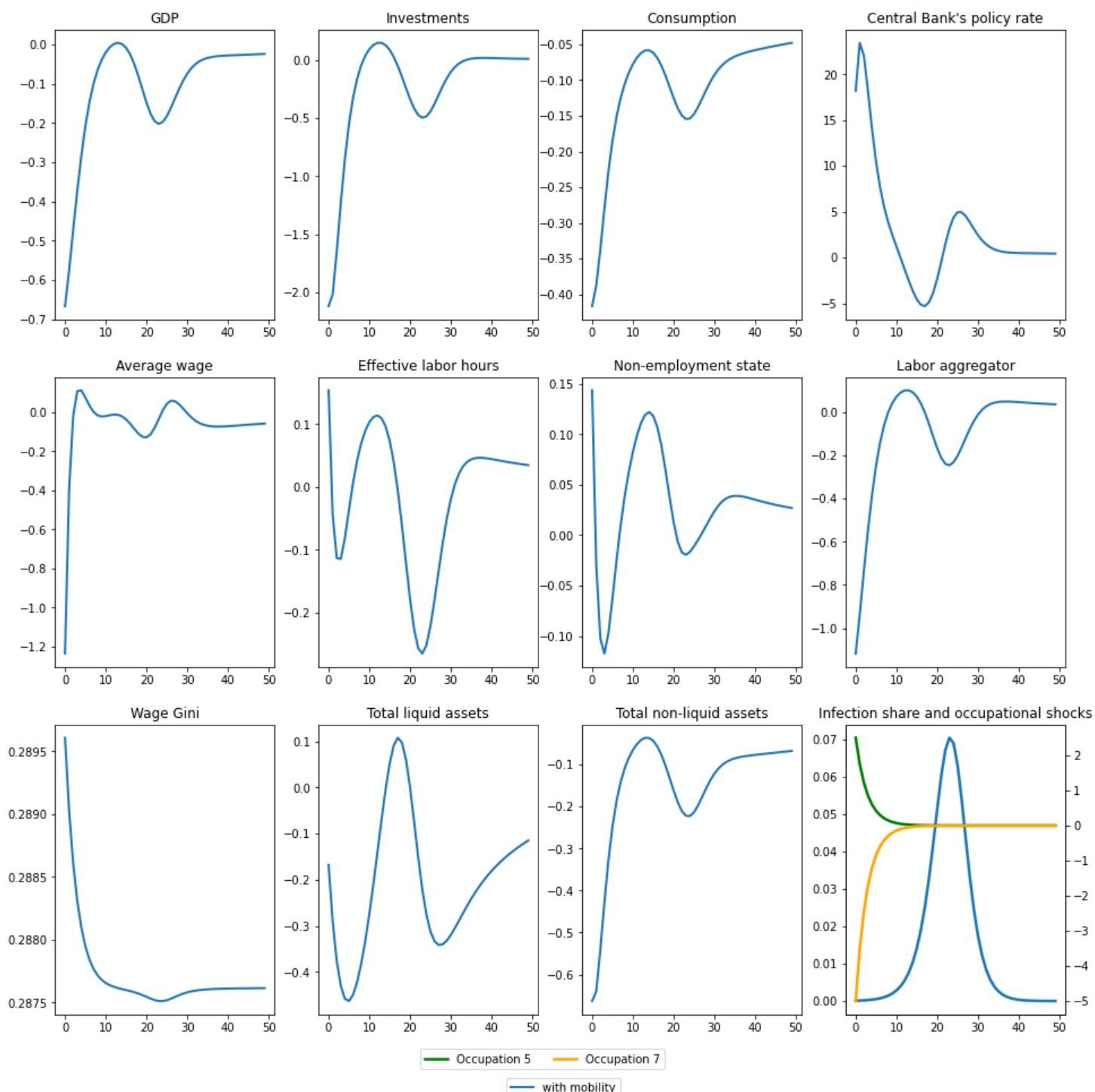

Figure 8: Impulse Responses to the Aggregate Labor Supply and Occupational Shocks.. The figure shows the percentage deviations of the selected variables from the steady state in response to the occupational shocks and to the infection shock. The occupational shock is a $2.5 \%$ increase in $\alpha_{5}$ and a $5 \%$ decrease in $\alpha_{7}$; each shock follows an $\operatorname{AR}(1)$ process with the persistence parameter 0.7 , such that the shock almost dissipates by the $13^{\text {th }}$ quarter. The infection shock is an increase in $\varepsilon_{\text {pandemic }}$ by $10^{-4}$. The figure shows the impulse responses from the model with the occupational mobility (in blue). The average wage is the weighted average wage across occupations where the weights are occupational employment shares in terms of efficiency units. The effective labor hours is the sum of the labor hours across occupations. The non-employment share shows the share of households that choose non-employment. Labor aggregator is $L_{s}$ and shows the aggregated labor used in the production. Wage Gini is presented in absolute values. The infected share is the share of currently infected people in the population. The occupational shocks presented in the last panel are shown on the right axis. X-axis shows the time in quarters. 


\section{Conclusions}

Inequality depends on idiosyncratic income shocks and skills. Occupational reallocation plays an important role of the economy's response to shocks and in shaping the inequality.

We propose a multi-sector and multi-occupation model in which agents are heterogeneous in skills and are exposed to idiosyncratic income risk, along the Bewley (1980)-Aiyagari (1994) tradition. We introduce Roy-type occupational choice driven by skill comparative advantage in the model and use the model to study economies response to shocks and the impact of shocks on inequality.

We summarize the contribution of our wok as follows. First, embedding an optimizing occupational mobility choice into a traditional heterogeneous agents model allows us to endogenize cross-sectional variation in earnings and to tie it to labor market conditions. Our model offers a two-way link between inequality and occupational choice: the position of the households on the wealth distribution affects, jointly with the skills, their mobility decisions. While the role of reallocation has been largely recognized as an indicator of economic resilience to shocks, the literature has so far focused on sectoral reallocation while neglecting the role of occupational reallocation. But worker skills are largely occupation- and not sector-specific. In addition, technological change emphases the importance of changes to occupational tasks.

Our model matches well long-run inequality and mobility distributions. Therefore, it provides a good laboratory economy to study the role of reallocation, particularly in response to large shocks. We apply the model to the recent pandemic recession, which featured a combination of aggregate labor supply and occupational labor demand shocks. We find that the occupational shocks foster reallocation, but deepen the recession and boost wage inequality. The aggregate labor supply shock (triggered by infection) triggers an increase in the number of people out of work but triggers little reallocation across occupations. Comparing our model with mobility to a model without mobility, we find that the model without mobility could underestimate the extent of the recessions and the changes in inequality over time. Finally, we show that the role of job specialization and dispersion in the skill-distribution, which captures workers' comparative advantage, affect the extent of reallocation, hence the dynamics of the recession and inequality. 


\section{References}

Abraham, Katharine G. and Lawrence F. Katz, "Cyclical Unemployment: Sectoral Shifts or Aggregate Disturbances?," Journal of Political Economy, 1986, 94 (3, Part 1), 507-522. Aiyagari, S. Rao, "Uninsured Idiosyncratic Risk and Aggregate Saving," The Quarterly Journal of Economics, 1994, 109 (3), 659-684.

_ _ and Mark Gertler, "Asset Returns with Transactions Costs and Uninsured Individual Risk," Journal of Monetary Economics, 1991, 27 (3), 311-331.

Alfaro, Laura, Ester Faia, Nora Lamersdorf, and Farzad Saidi, "Social Interactions in Pandemics: Fear, Altruism, and Reciprocity," Working Paper 27134, National Bureau of Economic Research 2020.

Alvarez, Fernando and Robert Shimer, "Search and Rest Unemployment," Econometrica, 2011, 79 (1), 75-122.

Antonovics, Kate and Limor Golan, "Experimentation and Job Choice," Journal of Labor Economics, 2012, 30 (2), 333-366.

Atkinson, Anthony B., Thomas Piketty, and Emmanuel Saez, "Top Incomes in the Long Run of History," Journal of Economic Literature, 2011, 49 (1), 3-71.

Auclert, Adrien, "Monetary Policy and the Redistribution Channel," American Economic Review, 2019, 109 (6), 2333-67.

and Matthew Rognlie, "Inequality and Aggregate Demand," Working Paper 24280,

National Bureau of Economic Research 2018.

, Bence Bardóczy, Matthew Rognlie, and Ludwig Straub, "Using the Sequence-Space Jacobian to Solve and Estimate Heterogeneous-Agent Models," Working Paper 26123, National Bureau of Economic Research 2019.

, Matthew Rognlie, and Ludwig Straub, "The Intertemporal Keynesian Cross," Working Paper 25020, National Bureau of Economic Research 2018. and ___ , "Micro Jumps, Macro Humps: Monetary Policy and Business Cycles in an Estimated HANK Model," Working Paper 26647, National Bureau of Economic Research 2020. 
Autor, David and Elisabeth Reynolds, "The Nature of Work after the COVID Crisis: Too Few Low-Wage Jobs," The Hamilton Project, 2020, (ESSAY 2020-14).

Autor, David H, Frank Levy, and Richard J. Murnane, "The Skill Content of Recent Technological Change: An Empirical Exploration," The Quarterly Journal of Economics, $2003,118(4), 1279-1333$.

Banerjee, Abhijit V. and Andrew F. Newman, "Occupational Choice and the Process of Development," Journal of Political Economy, 1993, 101 (2), 274-298.

Baqaee, David and Emmanuel Farhi, "Nonlinear Production Networks with an Application to the Covid-19 Crisis," Working Paper 27281, National Bureau of Economic Research 2020.

Barrero, Jose Maria, Nicholas Bloom, and Steven J. Davis, "Covid-19 Is Also a Reallocation Shock," Working Paper 27137, National Bureau of Economic Research 2020.

Barro, Robert J, José F. Ursúa, and Joanna Weng, "The Coronavirus and the Great Influenza Pandemic: Lessons from the "Spanish Flu" for the Coronavirus's Potential Effects on Mortality and Economic Activity," Working Paper 27137, National Bureau of Economic Research 2020.

Barry, John M., The Great Influenza: The Story of the Deadliest Pandemic in History, Penguin UK, 2020.

Bayer, Christian, Benjamin Born, Ralph Luetticke, and Gernot J Müller, "The Coronavirus Stimulus Package: How Large is the Transfer Multiplier?," Discussion Paper DP14600, CEPR 2020.

__ Ralph Lütticke, Lien Pham-Dao, and Volker Tjaden, "Precautionary Savings, Illiquid Assets, and the Aggregate Consequences of Shocks to Household Income Risk," Econometrica, 2019, 87 (1), 255-290.

Berger, David W, Kyle F Herkenhoff, and Simon Mongey, "Labor Market Power," Working Paper 25719, National Bureau of Economic Research 2019.

Bewley, Truman F., "The Permanent Income Hypothesis and Long-Run Economic Stability," Journal of Economic Theory, 1980, 22 (3), 377-394.

Bilbiie, Florin O, "Limited Asset Markets Participation, Monetary Policy and (Inverted) 
Aggregate Demand Logic," Journal of Economic Theory, 2008, 140 (1), 162-196.

Böhm, Michael J., Hans-Martin von Gaudecker, and Felix Schran, "Occupation, Growth, Skill Prices, and Wage Inequality," 2019.

Bonhomme, Stéphane, Thibaut Lamadon, and Elena Manresa, "Discretizing Unobserved Heterogeneity," University of Chicago, Becker Friedman Institute for Economics, 2017, (2019-16).

Boppart, Timo, Karl Harmenberg, John Hassler, Per Krusell, and Jonna Olsson, "Integrated Epi-Econ Assessment," Working Paper 28282, National Bureau of Economic Research 2020.

Boskin, Michael J., "A Conditional Logit Model of Occupational Choice," Journal of Political Economy, 1974, 82 (2, Part 1), 389-398.

Buera, Francisco J., "Non-Parametric Identification and Testable Implications of the Roy Model," Working Paper, Department of Economics, Northwestern University 2006.

Card, David, Ana Rute Cardoso, Joerg Heining, and Patrick Kline, "Firms and Labor Market Inequality: Evidence and Some Theory," Journal of Labor Economics, 2018, 36 (S1), S13-S70.

Chang, Yongsung and Sun-Bin Kim, "From Individual to Aggregate Labor Supply: a Quantitative Analysis Based on a Heterogeneous Agent Economy," International Economic Review, 2006, 47 (1), 3-24.

, Kyooho Kwon, and Richard Rogerson, "2018 Klein Lecture: Individual and Aggregate Labor Supply in Heterogeneous Agent Economies with Intensive and Extensive Margins," International Economic Review, 2019, 60 (1), 3-24.

Chernoff, Alex W. and Casey Warman, "COVID-19 and Implications for Automation," Working Paper, National Bureau of Economic Research 2020.

Chodorow-Reich, Gabriel and Johannes Wieland, "Secular Labor Reallocation and Business Cycles," Journal of Political Economy, 2020, 128 (6), 2245-2287.

_ and Loukas Karabarbounis, "The Cyclicality of the Opportunity Cost of Employment," Journal of Political Economy, 2016, 124 (6), 1563-1618.

Debortoli, Davide and Jordi Galí, "Monetary Policy with Heterogeneous Agents: Insights 
from TANK Models," 2017.

del Rio, Jose Mustre, "Wealth and Labor Supply Heterogeneity," Review of Economic Dynamics, 2015, 18 (3), 619-634.

Dunford, Nelson and Jacob T. Schwartz, Linear operators. Part I: General theory, John Wiley and Sons, 1958.

Dupor, Bill, Marios Karabarbounis, Marianan Kudlyak, and Saif M. Mehkari, "Regional Consumption Responses and the Aggregate Fiscal Multiplier," Working Paper 2018-04, FRB San Francisco 2018.

Eeckhout, Jan and Alireza Sepahsalari, "The Effect of Wealth on Worker Productivity," Discussion Paper 20/731, University of Bristol 2020.

Eichenbaum, Martin S., Sergio Rebelo, and Mathias Trabandt, "Inequality in Life and Death," Working Paper, Northwestern University 2020. , and __ , "The Macroeonomics of Epidemics," Working Paper 26882, National Bureau of Economic Research 2020.

Engle, Samuel, Jussi Keppo, Elena Kudlyak Marianna Quercioli, Lones Smith, and Andrea Wilson, "The Behavioral SIR Model, with Applications to the Swine Flu and COVID-19 Pandemics," Working Paper, University of Wisconsin 2020.

Farboodi, Maryam, Gregor Jarosch, and Robert Shimer, "Internal and External Effects of Social Distancing in a Pandemic," Working Paper 27059, National Bureau of Economic Research 2020.

Galí, Jordi and Mark Gertler, "Macroeconomic Modeling for Monetary Policy Evaluation," Journal of Economic Perspectives, 2007, 21 (4), 25-46.

Galor, Oded and Joseph Zeira, "Income Distribution and Macroeconomics," The Review of Economic Studies, 1993, 60 (1), 35-52.

Gathmann, Christina and Uta Schönberg, "How General Is Human Capital? A Task-Based Approach," Journal of Labor Economics, 2010, 28 (1), 1-49.

Gornemann, Nils, Keith Kuester, and Makoto Nakajima, "Doves for the rich, hawks for the poor? Distributional consequences of monetary policy," Discussion Paper DP11233, CEPR 2016. 
Grigsby, John, "Skill Heterogeneity and Aggregate Labor Market Dynamics," Working Paper, University of Chicago 2020.

Guerrieri, Veronica and Guido Lorenzoni, "Credit Crises, Precautionary Savings, and the Liquidity Trap," The Quarterly Journal of Economics, 2017, 132 (3), 1427-1467.

$\ldots$ _ _ Ludwig Straub, and Ivan Werning, "Macroeconomic Implications of COVID19: Can Negative Supply Shocks Cause Demand Shortages?," Working Paper 26918, National Bureau of Economic Research 2020.

Guvenen, Fatih, Burhan Kuruscu, Satoshi Tanaka, and David Wiczer, "Multidimensional Skill Mismatch," American Economic Journal: Macroeconomics, 2020, 12 (1), 210-44. Heathcote, Jonathan, Fabrizio Perri, and Giovanni L. Violante, "The Rise of US Earnings Inequality: Does the Cycle Drive the Trend?," Review of Economic Dynamics, 2020, 37, S181-S204.

_, Kjetil Storesletten, and Giovanni L. Violante, "The Macroeconomic Implications of Rising Wage Inequality in the United States," Journal of Political Economy, 2010, 118 (4), 681-722.

Heckman, James J. and Bo E. Honore, "The Empirical Content of the Roy Model," Econometrica, 1990, pp. 1121-1149.

Huggett, Mark, Gustavo Ventura, and Amir Yaron, "Sources of Lifetime Inequality," American Economic Review, 2011, 101 (7), 2923-54.

Iskhakov, Fedor, Thomas Jørgensen, John Rust, and Bertel Schjerning, "Estimating DiscreteContinuous Choice Models: The Endogenous Grid Method with Taste Shocks," Working Paper 2696079, Available at SSRN 2015.

Jaimovich, Nir, Itay Saporta-Eksten, Henry E Siu, and Yaniv Yedid-Levi, "The Macroeconomics of Automation: Data, Theory, and Policy Analysis," Working Paper 27122, National Bureau of Economic Research 2020.

Jovanovic, Boyan, "Job Matching and the Theory of Turnover," Journal of Political Economy, 1979, 87 (5, Part 1), 972-990.

Kaplan, Greg, Benjamin Moll, and Giovanni L. Violante, "Monetary Policy According to HANK," American Economic Review, 2018, 108 (3), 697-743. 
$\ldots$ _ _ Possibility Frontier for the U.S.," Working Paper 27794, National Bureau of Economic Research 2020.

Keane, Michael P. and Kenneth I. Wolpin, "The Career Decisions of Young Men," Journal of Political Economy, 1997, 105 (3), 473-522.

Kennan, John and James R. Walker, "The Effect of Expected Income on Individual Migration Decisions," Econometrica, 2011, 79 (1), 211-251.

Krueger, Dirk, Harald Uhlig, and Taojun Xie, "Macroeconomic Dynamics and Reallocation in an Epidemic: Evaluating the "Swedish Solution"," Working Paper 27047, National Bureau of Economic Research 2020.

Lilien, David M, "Sectoral Shifts and Cyclical Unemployment," Journal of Political Economy, 1982, 90 (4), 777-793.

Lise, Jeremy and Fabien Postel-Vinay, "Multidimensional Skills, Sorting, and Human Capital Accumulation," American Economic Review, 2020, 110 (8), 2328-76.

McFadden, Daniel and Paul Zarembka, Frontiers in Econometrics, Academic Press New York, 1974.

McKay, Alisdair and Ricardo Reis, "The Role of Automatic Stabilizers in the US Business Cycle," Econometrica, 2016, 84 (1), 141-194.

_ _ Emi Nakamura, and Jón Steinsson, "The Power of Forward Guidance Revisited," American Economic Review, 2016, 106 (10), 3133-58.

Moll, Benjamin, Lukasz Rachel, and Pascual Restrepo, "Uneven Growth: Automation's Impact on Income and Wealth Inequality," Working Paper 28440, National Bureau of Economic Research 2021.

Piketty, Thomas and Emmanuel Saez, "Inequality in the Long Run," Science, 2014, 344 (6186), 838-843.

Poletaev, Maxim and Chris Robinson, "Human Capital Specificity: Evidence from the Dictionary of Occupational Titles and Displaced Worker Surveys, 1984-2000," Journal of Labor Economics, 2008, 26 (3), 387-420.

Ravn, Morten O. and Vincent Sterk, "Job Uncertainty and Deep Recessions," Journal of 
Monetary Economics, 2017, 90, 125-141.

Roy, A. D., "Some Thoughts on the Distribution of Earnings," Oxford Economic Papers, 1951, 3 (2), 135-146.

Rust, John, "Optimal Replacement of GMC Bus Engines: An Empirical Model of Harold Zurcher," Econometrica, 1987, 55 (5), 999-1033.

Scheidel, Walter, The Great Leveler, Princeton University Press, 2020.

Schumpeter, Joseph, Capitalism, Socialism, and Democracy, Harper and Brothers, 1942.

Taber, Christopher and Rune Vejlin, "Estimation of a Roy/Search/Compensating Differential Model of the Labor Market," Econometrica, 2020, 88 (3), 1031-1069.

Yamaguchi, Shintaro, "Tasks and Heterogeneous Human Capital," Journal of Labor Economics, 2012, 30 (1), 1-53. 


\section{A. Derivations of Analytical Results}

Proposition 1 From the firm's optimization problem:

$$
l_{s, o, t}=\left(\frac{p_{s, t}\left(1-\nu_{s}\right) \alpha_{s, o}}{\mu_{p} p_{t} w_{o, t}}\right)^{\frac{1}{1-\sigma_{s}}}\left(z_{s} K_{s, t-1}^{\nu_{s}}\right)^{\frac{\sigma_{s}}{(1-\nu)\left(1-\sigma_{s}\right)}} y_{s, t}^{\frac{\sigma_{s}-1+\nu_{s}}{\left(1-\nu_{s}\right)\left(\sigma_{s}-1\right)}}
$$

Dividing the effective labor across occupations in the same sector delivers (from now on time sub-index is neglected):

$$
\frac{l_{s, o}}{l_{s, o^{\prime}}}=\left(\frac{\alpha_{s, o^{\prime}} w_{o}}{\alpha_{s, o} w_{o^{\prime}}}\right)^{\frac{-1}{1-\sigma_{s}}}
$$

The above shows that labor shares across occupations depend, for given wage distribution, on the following primitives: $\alpha_{s, o}, \sigma_{s}$. Note that the wage distribution is not a primitive in the model as it arises from the market clearing, hence is affected by labor supply, whose primitives include the $\Gamma$ matrix.

Next, the labor shares across sectors are derived. Using eq. (A.2), the definition of the production function and the definition of occupation aggregator the production function in each sector can be written as:

$$
\begin{gathered}
y_{s}=z_{s} K_{s}^{\nu_{s}}\left(\sum_{o^{\prime}=1}^{O} \alpha_{s, o^{\prime}} l_{s, o}^{\sigma_{s}}\left(\frac{\alpha_{s, o^{\prime}} w_{o}}{\alpha_{s, o} w_{o^{\prime}}}\right)^{\frac{\sigma_{s}}{1-\sigma_{s}}}\right)^{\frac{1-\nu_{s}}{\sigma_{s}}}= \\
z_{s} K_{s}^{\nu_{s}} l_{s, o}^{1-\nu_{s}}\left(\frac{w_{o}}{\alpha_{s, o}}\right)^{\frac{1-\nu_{s}}{1-\sigma_{s}}}\left(\sum_{o^{\prime}=1}^{O} \alpha_{s, o^{\prime}}^{\frac{1}{1-\sigma_{s}}} w_{o^{\prime}}^{\frac{-\sigma_{s}}{1-\sigma_{s}}}\right)^{\frac{1-\nu_{s}}{\sigma_{s}}}
\end{gathered}
$$

The prices in each sector are given by $p_{s}=\left(f_{s} \frac{Y}{y_{s}}\right)^{\frac{1}{n}} p$, therefore:

$$
p_{s}^{\frac{1}{1-\sigma_{s}}} y_{s, t}^{\frac{\sigma_{s}-1+\nu_{s}}{\left(1-\nu_{s}\right)\left(\sigma_{s}-1\right)}}=\left(f_{s} Y\right)^{\frac{1}{\eta\left(1-\sigma_{s}\right)}} p^{\frac{1}{1-\sigma_{s}}} y_{s}^{\frac{\eta\left(1-\nu_{s}-\sigma_{s}\right)-1+\nu_{s}}{\eta\left(1-\nu_{s}\right)\left(1-\sigma_{s}\right)}}
$$


The last equation can be substituted into eq. (A.1) and, after using eq. (A.4), this delivers:

$$
\begin{aligned}
l_{s, o}= & \left(\frac{\left(1-\nu_{s}\right)}{\mu_{p} p}\right)^{\frac{1}{1-\sigma_{s}}}\left(\frac{\alpha_{s, o}}{w_{o}}\right)^{\frac{1}{1-\sigma_{s}}}\left(z_{s} K_{z}^{\nu_{s}}\right)^{\frac{\sigma_{s}}{\left(1-\nu_{s}\right)\left(1-\sigma_{s}\right)}}\left(f_{s} Y\right)^{\frac{1}{\eta\left(1-\sigma_{s}\right)}} p^{\frac{1}{1-\sigma_{s}}} y_{s}^{\frac{\eta\left(1-\nu_{s}-\sigma_{s}\right)-1+\nu_{s}}{\eta\left(1-\nu_{s}\right)\left(1-\sigma_{s}\right)}} \\
= & \left(\frac{\left(1-\nu_{s}\right)}{\mu_{p} p}\right)^{\frac{1}{1-\sigma_{s}}}\left(\frac{\alpha_{s, o}}{w_{o}}\right)^{\frac{1}{1-\sigma_{s}}}\left(z_{s} K_{z}^{\nu_{s}}\right)^{\frac{\sigma_{s}}{\left(1-\nu_{s}\right)\left(1-\sigma_{s}\right)}}\left(f_{s} Y\right)^{\frac{1}{\eta\left(1-\sigma_{s}\right)}} p^{\frac{1}{1-\sigma_{s}}} . \\
& \cdot\left(z_{s} K_{s}^{\nu_{s}} l_{s, o}^{1-\nu_{s}}\left(\frac{w_{o}}{\alpha_{s, o}}\right)^{\frac{1-\nu_{s}}{1-\sigma_{s}}}\left(\sum_{o^{\prime}=1}^{O} \alpha_{s, o^{\prime}}^{\frac{1}{1-\sigma_{s}}} w_{o^{\prime}}^{\frac{-\sigma_{s}}{1-\sigma_{s}}}\right)^{\frac{1-\nu_{s}}{\sigma_{s}}}\right)^{\frac{\eta\left(1-\nu_{s}-\sigma_{s}\right)-1+\nu_{s}}{\eta\left(1-\nu_{s}\right)\left(1-\sigma_{s}\right)}}
\end{aligned}
$$

Collecting terms from eq. (A.6) delivers:

$$
\begin{aligned}
l_{s, o}= & {\left[\left(\frac{\left(1-\nu_{s}\right)}{\mu_{p} p}\right)^{\frac{1}{1-\sigma_{s}}}\left(f_{s} Y\right)^{\frac{1}{\eta\left(1-\sigma_{s}\right)}} p^{\frac{1}{1-\sigma_{s}}}\left(\frac{\alpha_{s, o}}{w_{o}}\right)^{\frac{\eta \nu_{s}+1-\nu_{s}}{\eta\left(1-\sigma_{s}\right)^{2}}}\left(z_{s} K_{s}^{\nu_{s}}\right)^{\frac{(\eta-1)\left(1-\nu_{s}\right)}{\eta\left(1-\nu_{s}\right)\left(1-\sigma_{s}\right)}}\right.} \\
& \left.\cdot\left(\sum_{o^{\prime}=1}^{O} \alpha_{s, o^{\prime}}^{\frac{1}{1-\sigma_{s}}} w_{o^{\prime}}^{\frac{-\sigma_{s}}{1-\sigma_{s}}}\right)^{\frac{(\eta-1)\left(1-\nu_{s}\right)-\eta \sigma_{s}}{\eta \sigma_{s}\left(1-\sigma_{s}\right)}}\right]^{\frac{\eta\left(1-\sigma_{s}\right)}{\eta \nu_{s}+1-\nu_{s}}}
\end{aligned}
$$

Setting $M_{s}=\left(\sum_{o^{\prime}=1}^{O} \alpha_{s, o^{\prime}}^{\frac{1}{1-\sigma_{s}}} w_{o^{\prime}}^{\frac{-\sigma_{s}}{1-\sigma_{s}}}\right)^{\frac{(\eta-1)\left(1-\nu_{s}\right)-\eta \sigma_{s}}{\eta \sigma_{s}\left(1-\sigma_{s}\right)}}$ and dividing by effective labor in the same occupation, but in different sectors by each other, delivers:

$$
\frac{l_{s^{\prime}, o}}{l_{s, o}}=\frac{\left[\left(1-\nu_{s^{\prime}}\right)^{\frac{1}{1-\sigma_{s^{\prime}}}} f_{s^{\prime}}^{\frac{1}{\eta\left(1-\sigma_{s^{\prime}}\right)}}\left(\frac{\alpha_{s^{\prime}, o}}{w_{o}}\right)^{\frac{\eta \nu_{s^{\prime}}+1-\nu_{s^{\prime}}}{\eta\left(1-\sigma_{s^{\prime}}\right)^{2}}}\left(z_{s^{\prime}} K_{s^{\prime}}^{\nu_{s^{\prime}}}\right)^{\frac{(\eta-1)\left(1-\nu_{s^{\prime}}\right)}{\eta\left(1-\nu_{s^{\prime}}\right)\left(1-\sigma_{s^{\prime}}\right)}} M_{s^{\prime}}\right]^{\frac{\eta\left(1-\sigma_{s^{\prime}}\right)}{\eta \nu_{s^{\prime}}+1-\nu_{s^{\prime}}}}}{\left[\left(1-\nu_{s}\right)^{\frac{1}{1-\sigma_{s}}} f_{s}^{\frac{1}{\eta\left(1-\sigma_{s}\right)}}\left(\frac{\alpha_{s, o}}{w_{o}}\right)^{\frac{\eta \nu_{s}+1-\nu_{s}}{\eta\left(1-\sigma_{s}\right)^{2}}}\left(z_{s} K_{s}^{\nu_{s}}\right)^{\frac{(\eta-1)\left(1-\nu_{s}\right)}{\eta\left(1-\nu_{s}\right)\left(1-\sigma_{s}\right)}} M_{s}\right]^{\frac{\eta\left(1-\sigma_{s}\right)}{\eta \nu_{s}+1-\nu_{s}}}}
$$

If $\sigma_{s}=\sigma_{s^{\prime}}$ and $\nu_{s}=\nu_{s^{\prime}}$ then the last ratio simplifies:

$$
\frac{l_{s^{\prime}, o}}{l_{s, o}}=\left(\left(\frac{f_{s^{\prime}}}{f_{s}}\right)^{\frac{1}{\eta\left(1-\sigma_{s}\right)}}\left(\frac{\alpha_{s^{\prime}, o}}{\alpha_{s, o}}\right)^{\frac{\eta \nu_{s}+1-\nu_{s}}{\eta\left(1-\sigma_{s}\right)^{2}}}\left(\frac{z_{s^{\prime}} K_{s^{\prime}}^{\nu_{s}}}{z_{s} K_{s}^{\nu_{s}}}\right)^{\frac{(\eta-1)\left(1-\nu_{s}\right)}{\eta\left(1-\nu_{s}\right)\left(1-\sigma_{s}\right)}}\left(\frac{M_{s^{\prime}}}{M_{s}}\right)\right)^{\frac{\eta\left(1-\sigma_{s}\right)}{\eta \nu_{s}+1-\nu_{s}}}
$$

The above shows that the labor shares across sectors depend upon the following primitives: $\alpha_{s, o}, \sigma_{s}, \nu_{s}, f_{s}$, and $z_{s}$. 
Proposition 2 From the intermediate firm's problem, the first-order condition for the demand for labor in each occupation in each sector reads as follows:

$$
l_{s, o, t}=\left(\frac{p_{s, t}\left(1-\nu_{s}\right) \alpha_{s, o}}{\mu_{p} p_{t} w_{o, t}}\right)^{\frac{1}{1-\sigma_{s}}}\left(z_{s} K_{s, t-1}^{\nu_{s}}\right)^{\frac{\sigma_{s}}{(1-\nu)\left(1-\sigma_{s}\right)}} y_{s, t}^{\frac{\left.\sigma_{s}-1+\nu_{s}\right)\left(\sigma_{s}-1\right)}{(1-1)}}
$$

Dividing the labor demand in one occupation by the labor demand in another, but for the same sector, delivers: $\frac{l_{s, o}}{l_{s, o^{\prime}}}=\left(\frac{\alpha_{s, o^{\prime}} w_{o}}{\alpha_{s, o} w_{o^{\prime}}}\right)^{\frac{-1}{1-\sigma_{s}}}$, which implies that:

$$
w_{o^{\prime}}^{\frac{\sigma_{s}}{\sigma_{s}-1}} l_{s, o}^{\sigma_{s}} \alpha_{s, o^{\prime}}^{\frac{-1}{\sigma_{s}-1}}=\left(\frac{w_{o}}{\alpha_{s, o}}\right)^{\frac{\sigma_{s}}{\sigma_{s}-1}} \alpha_{s, o^{\prime}} l_{s, o^{\prime}}^{\sigma_{s}}
$$

which upon expressing $l_{s, o}$ in terms of the other variables and upon some re-shuffling, it can be summed over both sides by $o^{\prime}$ to obtain: $L_{s}$ :

$$
l_{s, o}^{\sigma_{s}} \sum_{o^{\prime}=1}^{O} w_{o^{\prime}}^{\frac{\sigma_{s}}{\sigma_{s}-1}} \alpha_{s, o^{\prime}}^{\frac{-1}{\sigma_{s}-1}}=\left(\frac{w_{o}}{\alpha_{s, o}}\right)^{\frac{\sigma_{s}}{\sigma_{s}-1}} L_{s}^{\sigma_{s}}
$$

Isolating $l_{s, o}$ from the A.12 delivers $l_{s, o}=\left(\frac{w_{o}}{\alpha_{s, o}}\right)^{\frac{1}{\sigma_{s}-1}}\left(\frac{1}{\sum_{o^{\prime}=1}^{O} w_{o^{\prime}}^{\frac{\sigma_{s}}{\sigma_{s}-1}} \alpha_{s, o^{\prime}}^{\frac{-1}{\sigma_{s}-1}}}\right)^{\frac{1}{\sigma_{s}}} L_{s}$, which, after using Equation (A.10), can be written as:

$$
l_{s, o}=\left(\frac{w_{o}}{\alpha_{s, o}}\right)^{\frac{1}{\sigma_{s}-1}}\left(\frac{F_{s}}{\sum_{o^{\prime}=1}^{O} w_{o^{\prime}} l_{s, o^{\prime}}}\right)^{\frac{1}{\sigma_{s}}} L_{s}
$$

where $F_{s}=\left(\left(1-\nu_{s}\right) L_{s}^{-\sigma_{s}} \frac{Y}{\mu_{p}} y_{s}\right)^{\frac{1}{1-\sigma_{s}}}$. Using Equation (A.13), the elasticity of labor demand with respect to wages, with a continuum of occupations, is:

$$
\varepsilon_{l, w}=\frac{\partial l_{s, o}}{\partial w_{o}} \frac{w_{o}}{l_{s, o}}=\frac{1}{\sigma_{s}-1}
$$

while it reads as follows: $\varepsilon_{l, w}=\frac{1}{\sigma_{s}-1}\left(1-\frac{l_{s, o} w_{o}}{\sum_{o^{\prime}=1}^{O} l_{s, o^{\prime}} w_{o}^{\prime}}\right)$ under a finite number of occupations. The markup is then the inverse of the following expression (under an infinite number of occupations):

$$
\mu_{w}=\frac{\varepsilon_{l, w}}{\varepsilon_{l, w}+1}=\frac{1}{\sigma_{s}}
$$


and the inverse of the following expression with finite number of occupations: $\mu_{w}=$ $\frac{1-\frac{l_{s, o} w_{o}}{\sum_{o^{\prime}=1}^{O} l_{s, o^{\prime}}^{\prime} w_{o}^{\prime}}}{\sigma_{s}-\frac{l_{s, o} w_{o}}{\sum_{o^{\prime}=1}^{O} l_{s, o^{\prime}} w_{o}^{\prime}}}$. This proves part (1). When $\sigma_{s}=1$ the mark-up is also one and the labor aggregator is $L_{s}=\sum_{o=1}^{O} \alpha_{s, o} l_{s, o, t}$, hence occupations are perfectly substitutable. This proves part (2). When $\alpha_{s, o}=1$ for every $s$, then the total labor demand in each sector $s$ is equal to

$$
\sum_{o=1}^{O} l_{s, o}=\frac{\sum_{o=1}^{O} w_{o}^{\frac{1}{\sigma_{s}-1}}}{\left(\sum_{o^{\prime}=1}^{O} w_{o^{\prime}}^{\frac{\sigma_{s}}{\sigma_{s}-1}}\right)^{\frac{1}{\sigma_{s}}}} L_{s}
$$

When $\sigma_{s}=1$ it follows that: $l_{s, o}=I\left(w_{o}=\min _{o}\left(w_{o}\right)\right) L_{s}=\frac{1}{w_{o}} \frac{p_{s}}{p} \frac{\eta-1}{\eta}\left(1-\nu_{s}\right) y_{s} I\left(w_{o}=\min _{o}\left(w_{o}\right)\right)$ with $\sum_{o=1}^{O} l_{s, o}=L_{s}$ and where $I\left(w_{o}=\min _{o}\left(w_{o}\right)\right)$ is an indicator function that equals 1 for the occupation with the lowest wage.

Proposition 3 The production function is as follows:

$$
y_{s}=z_{s} K_{s}^{\nu_{s}} L_{s}^{1-\nu_{s}}=z_{s} K_{s}^{\nu_{s}}\left(\sum_{o=1}^{O} \alpha_{s, o} \sigma_{s, o}^{\sigma_{s}}\right)^{\frac{1-\nu_{s}}{\sigma_{s}}}
$$

Aggregating sectoral production functions into total output delivers:

$$
Y=\left(\sum_{s=1}^{S} f_{s}^{\frac{1}{\eta}} y_{s}^{\frac{\eta-1}{\eta}}\right)^{\frac{\eta}{\eta-1}}=\left[\sum_{s=1}^{S} f_{s}^{\frac{1}{\eta}}\left(z_{s} K_{s}^{\nu_{s}}\left(\sum_{o=1}^{O} \alpha_{s, o} l_{s, o}^{\sigma_{s}}\right)^{\frac{1-\nu_{s}}{\sigma_{s}}}\right)^{\frac{\eta-1}{\eta}}\right]^{\frac{\eta}{\eta-1}}
$$

The derivative of the total output with respect to $\sigma_{s}$ in a specific sector is:

$$
\begin{aligned}
\frac{\partial Y}{\partial \sigma_{s}} & =\frac{\eta}{\eta-1} Y^{\frac{1}{\eta}} f_{s}^{\frac{1}{\eta}}\left(z_{s} K_{s}^{\nu_{s}}\right)^{\frac{\eta-1}{\eta}} \frac{(\eta-1)}{\eta}\left(\sum_{o=1}^{O} \alpha_{s, o} l_{s, o}^{\sigma_{s}}\right)^{\frac{-\left(1-\nu_{s}\right)}{\eta \sigma_{s}}} \frac{\partial}{\partial \sigma_{s}}\left(\sum_{o=1}^{O} \alpha_{s, o} l_{s, o}^{\sigma_{s}}\right)^{\frac{1-\nu_{s}}{\sigma_{s}}}= \\
& Y^{\frac{1}{\eta}} f_{s}^{\frac{1}{\eta}}\left(z_{s} K_{s}^{\nu_{s}}\right)^{\frac{\eta-1}{\eta}}\left(\sum_{o=1}^{O} \alpha_{s, o} l_{s, o}^{\sigma_{s}}\right)^{\frac{-\left(1-\nu_{s}\right)}{\eta \sigma_{s}}}\left(\sum_{o=1}^{O} \alpha_{s, o} l_{s, o}^{\sigma_{s}}\right)^{\frac{1-\nu_{s}}{\sigma_{s}}}\left[-\frac{1-\nu_{s}}{\sigma_{s}^{2}} \ln \left(\sum_{o=1}^{O} \alpha_{s, o} l_{s, o}^{\sigma_{s}}\right)\right. \\
& \left.+\frac{1-\nu_{s}}{\sigma_{s}} \frac{1}{\left(\sum_{o=1}^{O} \alpha_{s, o} l_{s, o}^{\sigma_{s}}\right)}\left(\sum_{o=1}^{O} \alpha_{s, o} l_{s, o}^{\sigma_{s}} \ln \left(l_{s, o}\right)\right)\right]
\end{aligned}
$$


The derivative is positive if the expression in the square brackets is positive. The latter reads as follows:

$$
\left[-\frac{1-\nu_{s}}{\sigma_{s}^{2}} \ln \left(\sum_{o=1}^{O} \alpha_{s, o} l_{s, o}^{\sigma_{s}}\right)+\frac{1-\nu_{s}}{\sigma_{s}} \frac{1}{\left(\sum_{o=1}^{O} \alpha_{s, o} l_{s, o}^{\sigma_{s}}\right)}\left(\sum_{o=1}^{O} \alpha_{s, o} l_{s, o}^{\sigma_{s}} \ln \left(l_{s, o}\right)\right)\right] \geq 0
$$

Collecting the terms delivers:

$$
\frac{1}{\left(\sum_{o=1}^{O} \alpha_{s, o} l_{s, o}^{\sigma_{s}}\right)}\left(\sum_{o=1}^{O} \alpha_{s, o} l_{s, o}^{\sigma_{s}} \ln \left(l_{s, o}\right)\right) \geq \frac{1}{\sigma_{s}} \ln \left(\sum_{o=1}^{O} \alpha_{s, o} l_{s, o}^{\sigma_{s}}\right)
$$

Putting $\sigma_{s}$ on the left-hand side and then into the logarithm delivers:

$$
\left(\sum_{o=1}^{O} \alpha_{s, o} l_{s, o}^{\sigma_{s}} \ln \left(l_{s, o}^{\sigma_{s}}\right)\right) \geq\left(\sum_{o=1}^{O} \alpha_{s, o} l_{s, o}^{\sigma_{s}}\right) \ln \left(\sum_{o=1}^{O} \alpha_{s, o} l_{s, o}^{\sigma_{s}}\right)
$$

Given $\sum_{o=1}^{O} \alpha_{s, o}=1$, the last inequality holds for any values of $\sigma_{s}$ and $l_{s, o}$ due to Jensen's inequality ${ }^{13}$, which states that for a real convex function $\varphi$ and $\lambda_{1}+\ldots+\lambda_{n}=1$ if $\forall i \lambda_{i} \geq 0$ and $x_{i} \geq 0$ then :

$$
\varphi\left(\sum_{i=1}^{n} g\left(x_{i}\right) \lambda_{i}\right) \leq \sum_{i=1}^{n} \varphi\left(g\left(x_{i}\right)\right) \lambda_{i}
$$

Equation A.22 corresponds to a Jensen's inequality for $\varphi(x)=x \ln x, \lambda_{i}=\alpha_{s, o}, g\left(x_{i}\right)=l_{s, o}^{\sigma_{s}}$, $n=O$ and $i=o$.

\section{B. Computation Method}

The model is simulated by adapting the algorithm developed in Auclert et al. (2019). The underlying rationale of the method lies in finding a solution in sequence space, in which all operations like summation and multiplication are defined for sequences, see, for example, Dunford and Schwartz (1958)). Any variable in the model is therefore an infinite sequence. Multivariate Newton method is used to detect, for any variable, sequences such that the

13 https://encyclopediaofmath.org/index.php?title=Jensen_inequality, accessed 17.02.21 
initial conditions are satisfied, namely the model delivers a deterministic steady state, and all variables' dynamic paths are generated by the model equations given specified shock sequences. The solution relies on an approximation of the infinite sequences with finite ones. Auclert et al. (2019) show that such an approximation is good enough when the finite sequences considered are long enough.

The algorithm offers a log-linear approximated solution, whereby the sequences return to the same steady state, and a fully non-linear solution, which can accommodate the possibility of transitioning across steady states. Our mode features a SIR block, which implies a transition to a new steady state. For this reason the non-linear solution is adopted and adjusted to accommodate transition between the two steady states. Technically, initial and final steady states are inserted into the Newton method. The Jacobian and errors are then computed accordingly. The steady states are obtained from the deterministic version of the model equations and by normalizing aggregate output to 1 . The code is written in Python 3.7 .

Adapted Solution Algorithm with Fixed Point Routine The household optimization problem in the main text 3.1 is solved in two-stages. Numerically this has been implemented through a guess and verify procedure with the following steps:

1. Guess future value function, $W_{a}\left(\mathbf{z}_{j, t}, a_{t}, b_{t}, \phi_{o, t+1}\right)$,

$$
\begin{aligned}
& W_{b}\left(\left(\mathbf{z}_{j, t}, a_{t}, b_{t}, \phi_{o, t+1}\right) \text { where } W\left(\mathbf{z}_{j, t}, a_{t}, b_{t}, \phi_{o, t+1}\right)=\right. \\
& \sum_{o=1}^{O} V\left(\mathbf{z}_{j, t}, a_{t}, b_{t}, \phi_{o, t+1}\right) p\left(o_{t+1} \mid a_{t}, b_{t}, \mathbf{z}_{j, t}\right)
\end{aligned}
$$

2. For each occupation compute policy functions, i.e. calculate $a\left(\mathbf{z}_{j, t}, b_{t-1}, a_{t-1}\right)$ and $b\left(\mathbf{z}_{j, t}, b_{t-1}, a_{t-1}\right) \forall o$ (using F.O.C. s from the optimization problem in Equation (3))

3. Feed policy functions into the value and update: $V^{o}\left(\mathbf{z}_{j, t}, a_{t-1}, b_{t-1}\right)$

4. Compute occupation choice probabilities:

$$
\delta\left(o_{t} \mid \mathbf{z}_{j, t}, b_{t-1}, a_{t-1}\right)=\frac{\exp \left(V^{o}\left(\mathbf{z}_{j, t}, b_{t-1}, a_{t-1}\right)\right.}{\sum_{o_{t}^{\prime}} \exp \left(V^{o}\left(\mathbf{z}_{j, t}, b_{t-1}, a_{t-1}\right)\right.}
$$

5. Update guesses of $W_{a}\left(\mathbf{z}_{j, t}, a_{t}, b_{t}, \phi_{o, t+1}\right), W_{b}\left(\mathbf{z}_{j, t}, a_{t}, b_{t}, \phi_{o, t+1}\right)$ using envelope conditions and probabilities from step 4.

Aggregation is done using steady state distribution of the idiosyncratic income shocks, 
liquid and illiquid assets and the probabilities of being in each occupation which we assume we can handle as masses of our population. Mathematically the guess is used for the value function that reads as:

$$
\begin{aligned}
\bar{V}_{j}\left(e_{t}, a_{t-1}, b_{t-1}\right)= & \log \left[\sum _ { o t } \operatorname { e x p } \left(\operatorname { m a x } _ { a _ { t } ^ { o } , b _ { t } ^ { o } } u \left(\xi_{j, t}^{o}+\left(1+r_{t}^{a}\right) a_{t-1}+\left(1+r_{t}^{b}\right) b_{t-1}-\right.\right.\right. \\
& \left.\left.\left.\Phi\left(a_{t}^{o}, a_{t-1}\right)-a_{t}^{o}-b_{t}^{o}\right)+\lambda_{t}\left(b_{t}^{o}-\underline{b}\right)+\mu_{t} a_{t}^{o}+\beta E_{e_{t+1}} \bar{V}_{j}\left(e_{t}, a_{t}^{o}, b_{t}^{o}\right)\right)\right]
\end{aligned}
$$

where $\bar{V}_{j}\left(e_{t}, a_{t-1}, b_{t-1}\right)=E_{\phi} V_{j}\left(e_{t}, a_{t-1}, b_{t-1}, \phi_{t}\right)$. Using the above we compute the F.O.C.s with respect to liquid and illiquid assets as following:

$$
\begin{gathered}
u_{c}\left(c_{t} \mid o\right)=\lambda_{t}+\beta E_{e} \partial_{b} \bar{V}_{j}\left(e_{t+1}, a_{t}^{o}, b_{t}^{o}\right) \\
u_{c}\left(c_{t} \mid o\right)\left[1+\Phi_{1}\left(a_{t}, a_{t-1}\right)\right]=\mu_{t}+\beta E_{e} \partial_{a} \bar{V}_{j}\left(e_{t+1}, a_{t}^{o}, b_{t}^{o}\right)
\end{gathered}
$$

Envelope conditions:

$$
\begin{aligned}
& \partial_{b} \bar{V}_{t}\left(e_{t}, a_{t-1}, b_{t-1}\right)=\frac{\sum_{o t} \exp \left(\tilde{V}_{t}^{o}\left(e_{t}, b_{t-1}, a_{t-1}\right)\right) u^{\prime}\left(c_{t}^{*} \mid o_{t}\right)\left(1+r_{t}^{b}\right)}{\exp \left(\bar{V}_{t}\left(e_{t}, a_{t-1}, b_{t-1}\right)\right)} \\
& \partial_{a} \bar{V}_{t}\left(w_{t}, a_{t-1}, b_{t-1}\right)=\frac{\sum_{o t} \exp \left(\tilde{V}_{t}^{o}\left(e_{t}, b_{t-1}, a_{t-1}\right)\right) u^{\prime}\left(c_{t}^{*} \mid o_{t}\right)\left(1+r_{t}^{a}-\Phi_{2}\left(a_{t}^{*}, a_{t-1}\right)\right)}{\exp \left(\bar{V}_{t}\left(e_{t}, a_{t-1}, b_{t-1}\right)\right)}
\end{aligned}
$$

where $u_{c}\left(c_{t} \mid o\right)$ is the marginal utility of consumption in occupation $o$. The above operators are inserted in the computational method for heterogeneous agents by Auclert et al. (2019). 


\section{Constructing Occupational Clusters Using k-means}

Algorithm

The 8 clusters obtained through k-means algorithm can be summarized as follows:

1. Cluster1, Manual trade occupations, predominantly includes occupations from the Construction and extraction occupations, Installation, maintenance and repair occupations and Production occupations.

2. Cluster 2, Management and supervisory occupations, includes Management occupations, Business and financial operations occupations, Education, training and library occupations and Sales and related occupations., occupations of sales agents or supervisory workers from the Sales and related occupations group. Finally this cluster includes occupations from the social science field.

3. Cluster 3, Machine operators, includes residential construction occupations such as like carpet or drywall installers or masons, some occupations from Production occupations and others, such as machine operator from the Transportation and material moving occupations category.

4. Cluster 4, Engineering occupations, includes Management occupations, Computer and mathematical science occupations, Life, physical and social science occupations and Architecture and engineering occupations. The cluster also includes occupations, such as cashier and counter clerks from the Sales and related occupations group, but also scientific occupations in life and physical science (occupations contain the key word scientist)

5. Cluster 5, Healthcare and community occupations, is predominantly populated by Healthcare practitioner and technical occupations and almost all Community and social service occupations.

6. Cluster 6, Personal service occupations, mainly technical-support occupations from the larger Architecture and engineering occupations, Life, physical and social science occupations and Computer and mathematical science occupations groups.

7. Cluster 7, Technical-Support occupations, is mainly populated with occupations Food 
Table 7: Occupational Clusters and Major Occupation Groups

Occupation Clusters

\section{Detailed Occupation Groups}

Management occupations

Business and financial operations occupations

Computer and mathematical science occupations

Architecture and engineering occupations

Life, physical, and social science occupations

Community and social service occupation

Legal occupations

Education, training, and library occupations

Arts, design, entertainment, sports, and media occupations

Healthcare practitioner and technical occupations

Healthcare support occupations

Protective service occupations

Food preparation and serving related occupations

Building and grounds cleaning and maintenance occupations

Personal care and service occupations

Sales and related occupations

Office and administrative support occupations

Farming, fishing, and forestry occupations

Construction and extraction occupations

Installation, maintenance, and repair occupations

Production occupations

Transportation and material moving occupations

\begin{tabular}{lllllllll}
1 & 2 & 3 & 4 & 5 & 6 & 7 & 8 & Total \\
\hline 0 & 19 & 0 & 4 & 1 & 2 & 0 & 0 & 26 \\
0 & 17 & 0 & 2 & 1 & 0 & 0 & 5 & 25 \\
0 & 4 & 0 & 6 & 0 & 1 & 0 & 0 & 11 \\
0 & 0 & 0 & 18 & 0 & 3 & 0 & 0 & 21 \\
0 & 7 & 0 & 9 & 0 & 7 & 0 & 0 & 23 \\
0 & 3 & 0 & 0 & 2 & 0 & 0 & 0 & 5 \\
0 & 2 & 0 & 0 & 0 & 0 & 0 & 2 & 4 \\
0 & 7 & 0 & 0 & 0 & 0 & 3 & 1 & 11 \\
0 & 5 & 0 & 0 & 0 & 6 & 3 & 3 & 17 \\
0 & 1 & 0 & 0 & 23 & 2 & 0 & 1 & 27 \\
0 & 0 & 0 & 0 & 2 & 1 & 3 & 0 & 6 \\
2 & 1 & 0 & 0 & 7 & 2 & 4 & 0 & 16 \\
0 & 0 & 1 & 0 & 0 & 2 & 9 & 0 & 12 \\
0 & 0 & 2 & 0 & 0 & 2 & 2 & 0 & 6 \\
0 & 2 & 1 & 0 & 1 & 1 & 12 & 1 & 18 \\
0 & 7 & 0 & 1 & 0 & 0 & 5 & 4 & 17 \\
0 & 3 & 3 & 0 & 0 & 2 & 10 & 30 & 48 \\
3 & 0 & 2 & 0 & 0 & 2 & 1 & 0 & 8 \\
20 & 0 & 19 & 0 & 0 & 1 & 0 & 0 & 40 \\
30 & 0 & 6 & 0 & 0 & 1 & 0 & 0 & 37 \\
10 & 0 & 56 & 0 & 0 & 5 & 4 & 0 & 75 \\
6 & 0 & 20 & 0 & 0 & 5 & 2 & 0 & 33 \\
\hline 1 & 78 & & & & & 4 & 58 & \\
\end{tabular}

$\begin{array}{llllllll}71 & 78 & 11040 & 37 & 45 & 58 & 47 & 486\end{array}$

Total

preparation and serving related occupations, Sales and related occupations, Healthcare support occupations and Personal care and service occupations.

8. Cluster 8, Office and administrative support occupations, consists mainly of Office and administrative support occupations.

Table 7 cross-tabulates the major occupation group and our assignment to one of the 8 clusters for the 3-digit occupations. 


\section{Appendix Tables}

Table 8: Sectors: Capital and labor Shares, KLEMS Data, Averages 1987-2015

\begin{tabular}{|c|c|c|}
\hline Sectors Name & Capital Share & labor Share \\
\hline Accommodation and Food Service & 0.35 & 0.65 \\
Community, Social and Pers. Services & 0.19 & 0.81 \\
Construction & 0.17 & 0.83 \\
Electr., Gas and Water Supply & 0.70 & 0.30 \\
Financial and Insurance & 0.41 & 0.59 \\
Information and Communication & 0.50 & 0.50 \\
Manufacturing & 0.44 & 0.56 \\
Mining and Qarrying & 0.68 & 0.32 \\
Scien., Tech., Admin. and Sup. Service & 0.18 & 0.82 \\
Real Estate Activities & 0.94 & 0.06 \\
Transportation and Storage & 0.27 & 0.73 \\
Wholesale and Retail Trade & 0.42 & 0.58 \\
Total & 0.44 & 0.56 \\
\hline
\end{tabular}

\section{E. Other Quantitative Results}

Figure 9 shows the dynamics of selected variables to an occupational shock under the Taylor rule. Reallocation across occupations (second panel, third row) appears enhanced compared to the case of the ZLB policy presented in the main text. As a result less workers opt out of the labor force, but rather reallocate to other jobs. As cross-occupational reallocation prevails, under this policy stance the model with mobility tames the recession compared to the one without. In absence of the sheltering provided by the expansionary policy workers reallocate more actively. This provides an interesting exchange between a policy, the ZLB, that fosters demand by enhancing income capacity, and a policy, the Taylor rule, that lubricates the labor market by activating mobility.

Figure 10 below presents impulse responses of the usually selected variables to an adverse occupational shock to occupation 2 , which includes sales, education, but also managerial positions in business and finance. 

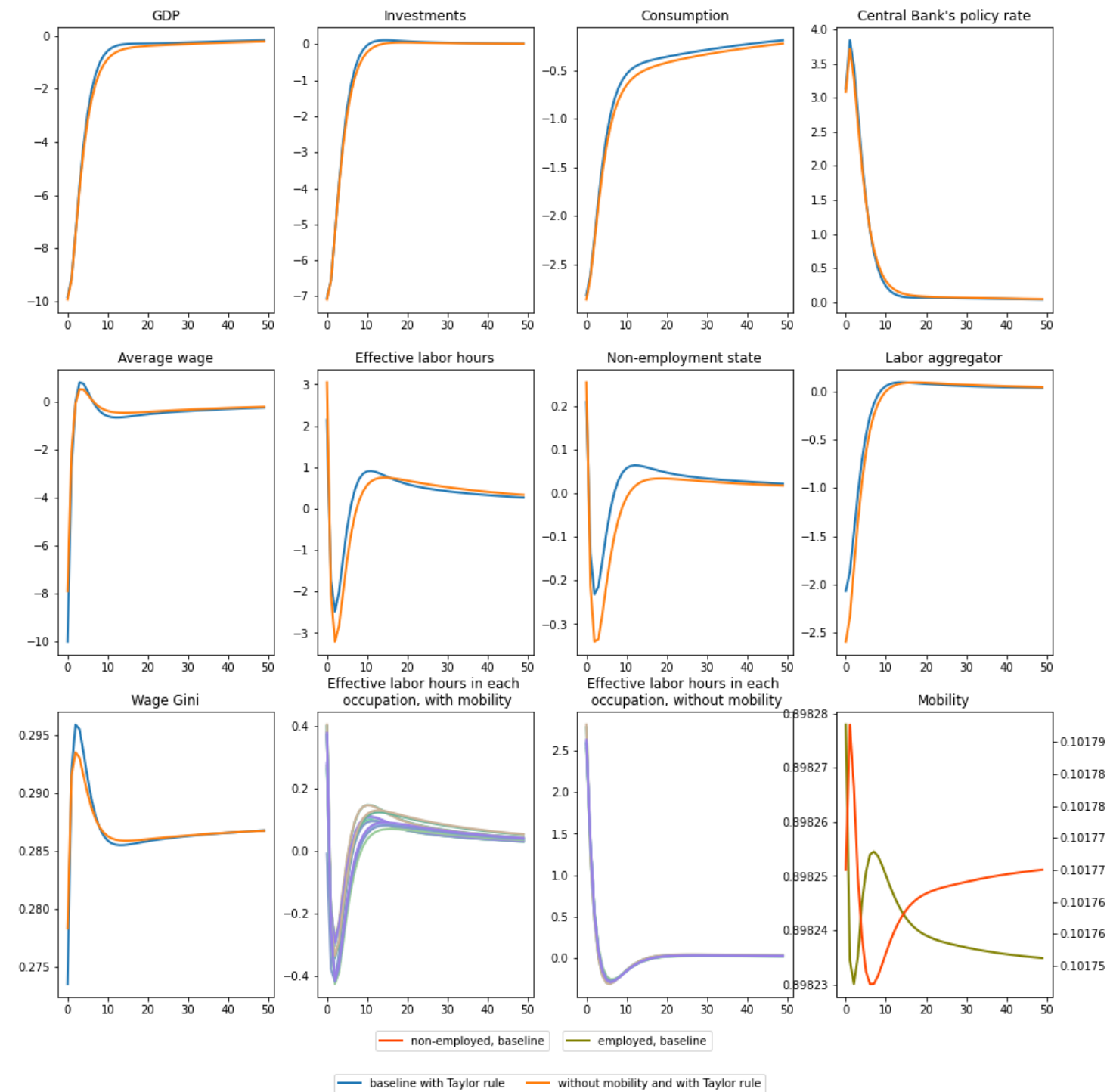

Figure 9: Impulse Responses to an Occupational Shock. The figure shows the percentage deviations of the selected variables from the steady state in response to an occupational shock. The occupational shock is a $10 \%$ increase in $\alpha_{5}$ and a $60 \%$ decrease in $\alpha_{7}$; each shock follows an $\operatorname{AR}(1)$ process with the persistence parameter 0.7 , such that the shock almost dissipates by the $13^{\text {th }}$ quarter. The figure shows the impulse responses from the model with the occupational mobility (in blue) and from the model without it (in orange). Central Bank follows the Taylor rule. The average wage is the weighted average wage across occupations where the weights are occupational employment shares in terms of efficiency units. The effective labor hours is the sum of the labor hours across occupations. The non-employment share shows the share of households that choose non-employment. Labor aggregator is $L_{s}$ and shows the aggregated labor used in the production. Wage Gini is presented in absolute values. Occupational labor dynamics are shown in the last row, where each line corresponds to the effective labor hours in the specified occupation. Mobility panel shows probability (aggregated across households and occupations) of being employed and probability of being in the non-employed state (aggregated across households). Probability of being in the non-employed state is shown on the right axis. $\mathrm{X}$-axis shows the time in quarters. 

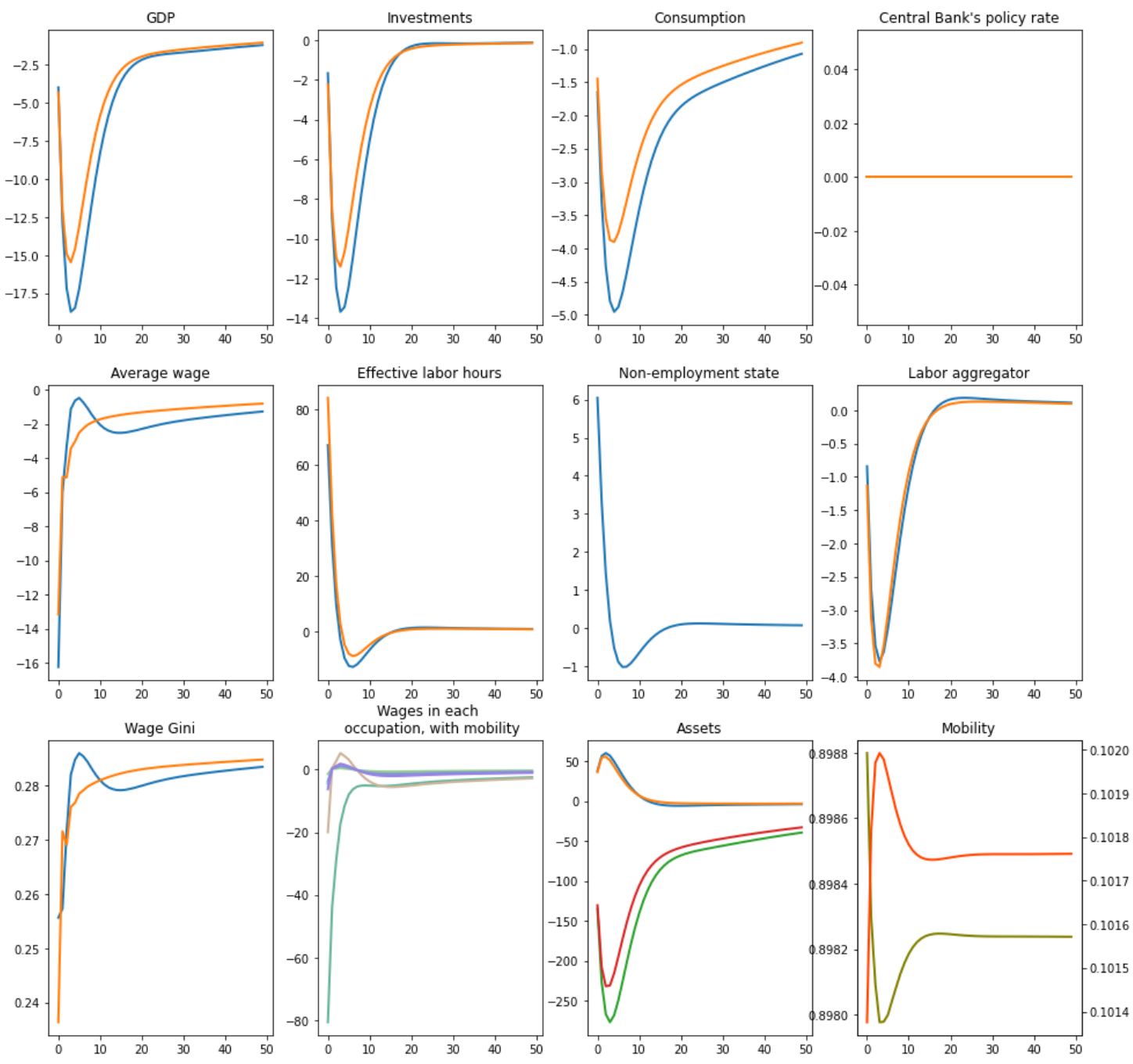

$$
\begin{aligned}
& \begin{array}{llll}
\text { occ1 } & \text { - occ } 3 & \text { - occ } 5 & \text { - occ7 } \\
\text { occ } 2 & \text { occ } 4 & \text { occ } 6 & \text { - occ } 8
\end{array} \\
& \text { — liquid, mobility — liquid, no mobility — non-liquid, mobility — non-liquid, no mobility } \\
& \text { — non-employment }- \text { employement }
\end{aligned}
$$

Figure 10: Impulse Responses to an Occupational Shock in Occupation 2 (Business, Sales, Education.). The figure shows the percentage deviations of the selected variables from the steady state in response to an occupational shock. The occupational shock is a $60 \%$ decrease in $\alpha_{2}$; the shock follows an $\mathrm{AR}(1)$ process with the persistence parameter 0.7 , such that the shock almost dissipates by the $13^{\text {th }}$ quarter. The figure shows the impulse responses from the model with the occupational mobility (in blue) and from the model without it (in orange). The average wage is the weighted average wage across occupations where the weights are occupational employment shares in terms of efficiency units. The effective labor hours is the sum of the labor hours across occupations. The non-employment share shows the share of households that choose non-employment. Labor aggregator is $L_{s}$ and shows the aggregated labor used in the production. Wage Gini is presented in absolute values. Occupational wage dynamics are shown in the last row, where each line corresponds to the wage in the specified occupation. Mobility panel shows probability (aggregated across households and occupations) of being employed and probability of being in the non-employed state (aggregated across households). Probability of being in the non-employed state is shown on the right axis. $\mathrm{X}$-axis shows the time in quarters.

Figure 11 below shows the responses of the wage Gini to occupational shocks hitting high-wage occupations (right panel) or low-wage occupations (left panel). 

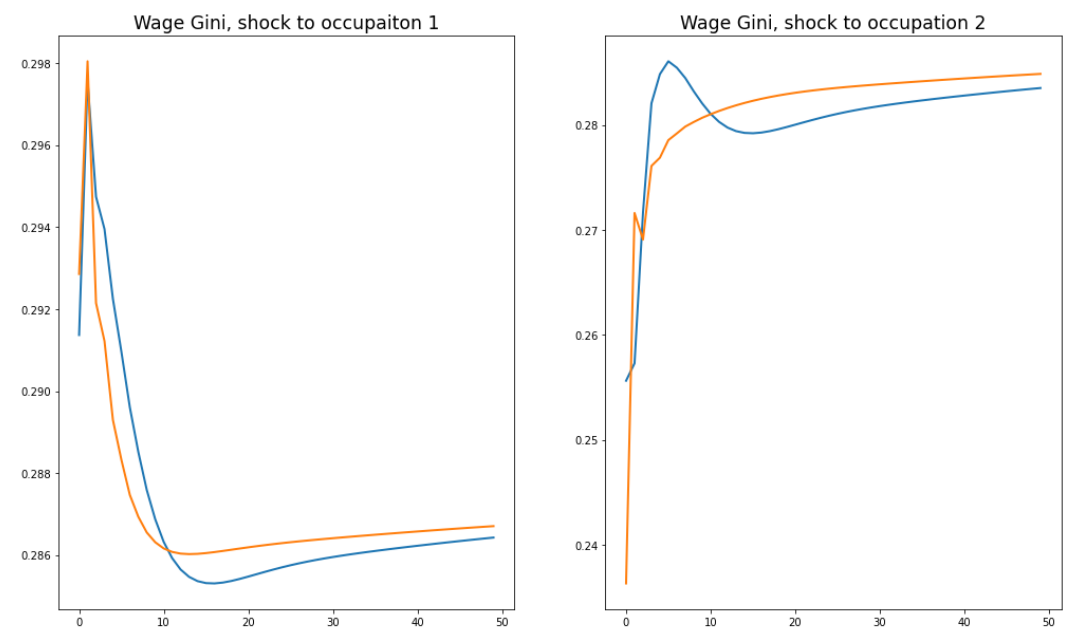

Figure 11: Gini Coefficients for Different Occupational Shocks. The figure shows the wage Gini coefficients for the occupational shock to occupation 1 (Construction) and for the shock to occupation 2 (Management and Financial). The shock is a 60\% decrease in $\alpha_{1}$ or $\alpha_{2}$ respectively; each shock follows an $\mathrm{AR}(1)$ process with the persistence parameter 0.7 , such that the shock almost dissipates by the $13^{\text {th }}$ quarter. The figure shows wage Gini coefficients from the model with the occupational mobility (in blue) and from the model without it (in orange). Wage Gini coefficients are presented in absolute values.

\section{F. Wealth Distribution Graphs}
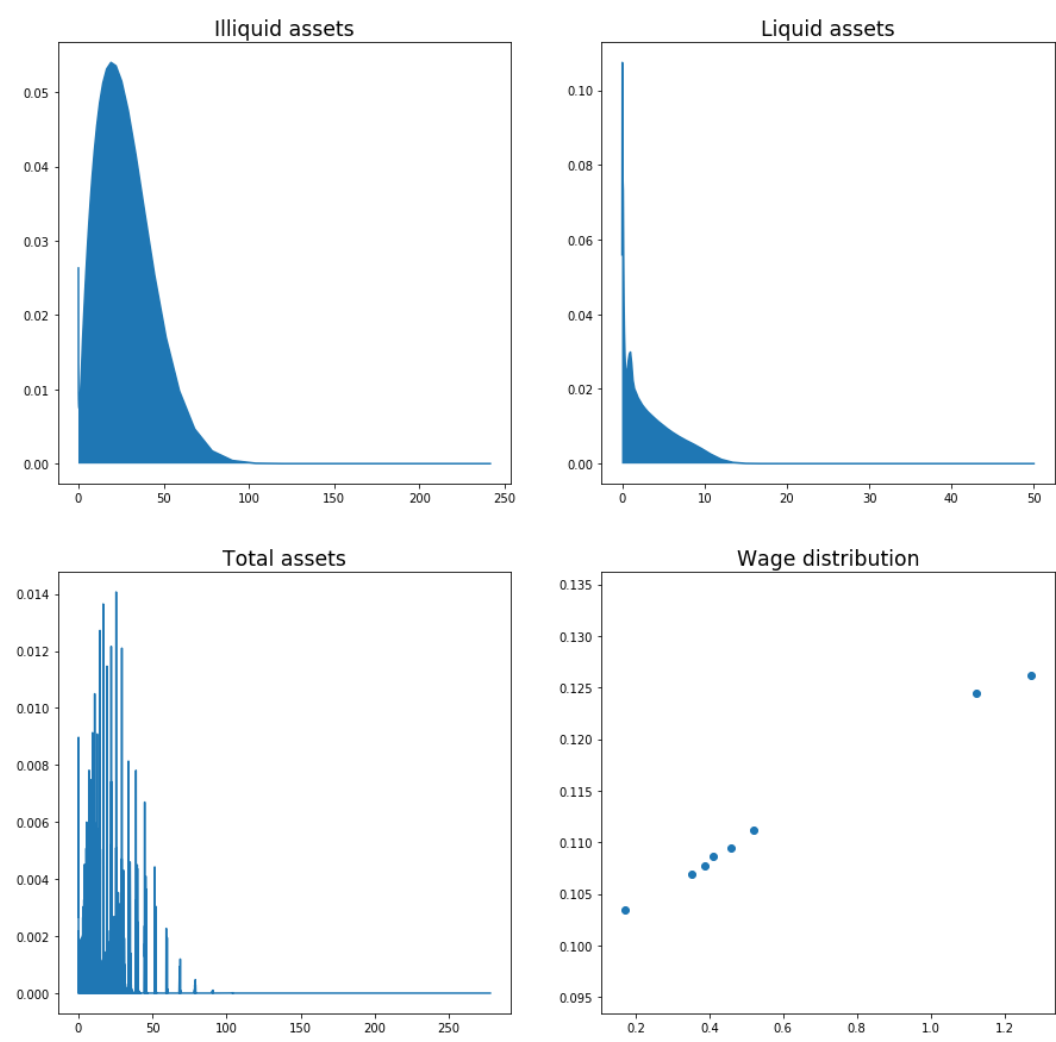

Figure 12: Distributions in the Steady State. The figure shows the distribution of total wealth, liquid/non-liquid assets or wages. $\mathrm{X}$-axis represents wealth/wage values and $\mathrm{Y}$-axis represents probability densities. The wage distribution plots wages for each of the eight occupations (x-axis) against the share of total population working in each occupation. The non-liquid and the wealth distributions are cut at the upper tail (the total probability of the cut parts is $10^{-13}$ ). 